\title{
Liquid-liquid phase separation and morphology of internally mixed dicarboxylic acids/ammonium sulfate/water particles
}

\author{
M. Song ${ }^{1}$, C. Marcolli ${ }^{1}$, U. K. Krieger ${ }^{1}$, A. Zuend ${ }^{2}$, and T. Peter ${ }^{1}$ \\ ${ }^{1}$ Institute for Atmospheric and Climate Science, ETH Zurich, 8092, Zurich, Switzerland \\ ${ }^{2}$ Department of Chemical Engineering, California Institute of Technology, Pasadena, 91125, California, USA
}

Correspondence to: M. Song (mijung.song@env.ethz.ch)

Received: 11 October 2011 - Published in Atmos. Chem. Phys. Discuss.: 28 October 2011

Revised: 28 February 2012 - Accepted: 6 March 2012 - Published: 13 March 2012

\begin{abstract}
Knowledge of the physical state and morphology of internally mixed organic/inorganic aerosol particles is still largely uncertain. To obtain more detailed information on liquid-liquid phase separation (LLPS) and morphology of the particles, we investigated complex mixtures of atmospherically relevant dicarboxylic acids containing 5, 6, and 7 carbon atoms (C5, C6 and C7) having oxygen-to-carbon atomic ratios $(\mathrm{O}: \mathrm{C})$ of $0.80,0.67$, and 0.57 , respectively, mixed with ammonium sulfate (AS). With micrometer-sized particles of $\mathrm{C} 5 / \mathrm{AS} / \mathrm{H}_{2} \mathrm{O}, \mathrm{C} 6 / \mathrm{AS} / \mathrm{H}_{2} \mathrm{O}$ and $\mathrm{C} 7 / \mathrm{AS} / \mathrm{H}_{2} \mathrm{O}$ as model systems deposited on a hydrophobically coated substrate, laboratory experiments were conducted for various organic-to-inorganic dry mass ratios (OIR) using optical microscopy and Raman spectroscopy. When exposed to cycles of relative humidity (RH), each system showed significantly different phase transitions. While the $\mathrm{C} 5 / \mathrm{AS} / \mathrm{H}_{2} \mathrm{O}$ particles showed no LLPS with OIR $=2: 1,1: 1$ and $1: 4$ down to $20 \% \mathrm{RH}$, the $\mathrm{C} 6 / \mathrm{AS} / \mathrm{H}_{2} \mathrm{O}$ and $\mathrm{C} 7 / \mathrm{AS} / \mathrm{H}_{2} \mathrm{O}$ particles exhibit LLPS upon drying at RH 50 to $85 \%$ and $\sim 90 \%$, respectively, via spinodal decomposition, growth of a second phase from the particle surface or nucleation-and-growth mechanisms depending on the OIR. This suggests that LLPS commonly occurs within the range of $\mathrm{O}: \mathrm{C}<0.7$ in tropospheric organic/inorganic aerosols. To support the comparison and interpretation of the experimentally observed phase transitions, thermodynamic equilibrium calculations were performed with the AIOMFAC model. For the C $7 / \mathrm{AS} / \mathrm{H}_{2} \mathrm{O}$ and $\mathrm{C} 6 / \mathrm{AS} / \mathrm{H}_{2} \mathrm{O}$ systems, the calculated phase diagrams agree well with the observations while for the $\mathrm{C} 5 / \mathrm{AS} / \mathrm{H}_{2} \mathrm{O}$ system LLPS is predicted by the model at RH below $60 \%$ and higher AS concentration, but was not observed in the experiments.
\end{abstract}

Both core-shell structures and partially engulfed structures were observed for the investigated particles, suggesting that such morphologies might also exist in tropospheric aerosols.

\section{Introduction}

Aerosol particles affect the Earth's energy budget directly by scattering and/or absorbing solar radiation and indirectly by acting as cloud condensation and ice nuclei modifying cloud properties (Yu et al., 2006; IPCC, 2007). These effects are influenced by the aerosol size, physical state, chemical composition and morphology, which also affect the particle hygroscopicity (Hanel, 1976; Martin, 2000). Therefore, the interrelation between chemical composition and aerosol phase might be critical to attain a correct description of aerosol effects on climate.

The hygroscopic behavior of inorganic salts such as ammonium sulfate (AS), sodium chloride and ammonium nitrate have been well characterized (Tang and Munkelwitz, 1984, 1994; Cziczo et al., 1997; Martin, 2000). When crystalline particles of these inorganic salts are exposed to increasing relative humidity (RH), they take up water from the gas phase and become solution droplets at their deliquescence relative humidity (DRH). In turn, when the RH is decreased, the smaller solution droplets may reach high supersaturation before they crystallize and lose their water to the gas phase at the efflorescence relative humidity (ERH). While the inorganic aerosol constituents are relatively small in number and well known, the chemical composition of the organic matter is highly complex with a large fraction still 
unidentified (Decesari et al., 2006; Goldstein and Galbally, 2007). Field measurements showed that organic aerosol accounts for 30 to $80 \%$ of the total fine aerosol mass in various regions (Murphy et al., 2006; Zhang et al., 2007; Hallquist et al., 2009). Considering the high multitude of organic components present in the particle phase, the organics are expected to be in the liquid state or an amorphous solid state even at low RH in the atmosphere (Marcolli et al., 2004). Owing to their larger size, deliquesced particles scatter the solar radiation more effectively than their effloresced analogs (Martin, 2000). Furthermore, liquid organic particles become increasingly viscous with decreasing temperatures and may attain a glassy state instead of efflorescing. Therefore, ice nucleation and ice crystal growth can be significantly impeded in organic-rich aerosol particles in the upper troposphere (Murray, 2008; Zobrist et al., 2008). Organic aerosol compositions span a large range from highly oxidized secondary matter to hydrophobic primary organic matter, and are expected to separate into a more polar and a less polar phase (Pankow, 2003; Chang and Pankow, 2006; Zuend et al., 2010). Modeling particulate matter formation by forcing a single condensed phase when in reality two liquid phases are the preferred state leads to errors in the partitioning of water and semivolatile compounds, and thus to errors in the predicted composition and amount of particulate matter (PM), which may lead to an underprediction of organic PM by as much as $50 \%$ (Erdakos and Pankow, 2004; Chang and Pankow, 2006; Zuend et al., 2010).

Organic and inorganic substances have been found to coexist internally mixed within aerosol particles (Lee et al., 2002; Murphy et al., 2006). Interactions between organic and inorganic components within an aerosol particle can influence DRH and ERH of inorganic salts or even totally suppress crystallization (Marcolli et al., 2004; Parsons et al., 2006). Furthermore, liquid-liquid phase separation (LLPS) into a mainly polar inorganic and a less polar organicrich phase during humidity cycles may occur (Marcolli and Krieger, 2006). To date direct experimental evidence of the physical state and morphology of submicron aerosols is scarce. Continuous water uptake observed in H-TDMA measurements indicates partially or totally liquid particles (e.g. Weingartner et al., 2002; Swietlicki et al., 2008). Martin et al. (2008), on the other hand, have observed deliquescence/efflorescence behavior of ambient particles in Oklahoma. Particle bouncing in an aerosol impactor and electron microscopy of biogenic secondary organic aerosol particles has been interpreted as evidence for solid amorphous, i.e. glassy particles at $\mathrm{RH}<20 \%$ (Virtanen et al., 2010). However, there is no measurement technique available at present that could observe LLPS in ambient aerosols directly. Therefore, laboratory experiments and model calculations are needed to infer the physical state for a given chemical aerosol composition. Zuend et al. (2010) recently presented a liquid-liquid equilibrium and gas/particle partitioning model that allows the reliable computation of LLPS of multicomponent systems. They use as a basis the groupcontribution model called Aerosol Inorganic-Organic Mixtures Functional groups Activity Coefficients (AIOMFAC) (Zuend et al., 2008). Calculations that they performed for ternary and multicomponent alcohol/polyol-water-salt mixtures suggest that liquid-liquid equilibria are indeed a prevalent feature of organic-inorganic aerosol systems. LLPS in smog chamber experiments is supported by a recent study of phase transitions and growth factors of mixed particles consisting of AS and secondary organic material prepared from $\alpha$-pinene ozonolysis that are consistent with a model of phase separation into an aqueous electrolyte phase and an organicrich phase in individual particles (Smith et al., 2011).

Particles consisting of two liquid phases can adopt different morphologies, e.g. fully engulfed core-shell structures or asymmetric partial engulfed structures. Knowledge of the aerosol morphology is important for determining the nature of the gas-particle interface, and thus the rate of heterogeneous chemical reactions, and the rate of water uptake (Cai et al., 1996; Fuzzi et al., 2006; Kwamena et al., 2010, Reid et al., 2011). Formation of organic coatings by condensation of monoterpene oxidation products onto aqueous sulfate particles is suspected to significantly reduce the heterogeneous hydrolysis rates of $\mathrm{N}_{2} \mathrm{O}_{5}$ (Folkers et al., 2003; Anttila et al., 2006, 2007). Model simulations for Europe suggest that this process could decrease particulate nitrate concentrations by up to $90 \%$ (Riemer et al., 2009). Strong reduction of $\mathrm{N}_{2} \mathrm{O}_{5}$ hydrolysis rates have also been observed for sulfuric acid and seasalt aerosols that were coated with organic surfactants (Thornton and Abbatt, 2005; McNeill et al., 2006; Cosman and Bertram, 2008; Cosman et al., 2008).

Ciobanu et al. (2009) used optical microscopy and microRaman spectroscopy to investigate LLPS of micrometersized droplets consisting of poly(ethylene glycol)-400 (PEG400)/AS/water. The resulting morphology was an aqueous AS inner phase surrounded by a mainly PEG-400 containing outer phase. Core-shell morphologies have also been observed by Bertram et al. (2011) for mixed organic/AS particles deposited on a hydrophobically coated substrate. However, Kwamena et al. (2010) and Reid et al. (2011) have shown in model calculations and experiments that the adoption of a partially engulfed structure should predominate with the organic component forming a surface lens when the solubility of the organic component and the salting-out of the organic component to the surface by the presence of concentrated inorganic solutes in the aqueous phase are considered.

Previous studies on phase transitions of single aerosol particles have mostly been performed with one organic substance in the presence of AS (Parsons et al., 2006; Ling and Chan, 2008; Ciobanu et al., 2009; Yeung et al., 2009; Bertram et al., 2011). Studies on more complex organic mixtures are needed to obtain insight into the phase transitions of organic/inorganic aerosols considering atmospheric aerosol composition. In this study, we investigate single particles containing different dicarboxylic acids and AS 
during humidity cycles. Dicarboxylic acids are one of the most abundant organic compound classes in the troposphere (Decesari et al., 2006; Gilardoni et al., 2009; Hawkins et al., 2010). For our model systems, we mix together three isomeric acids to better mimic the complexity of real aerosol compositions. Three mixtures with $\mathrm{C} 5, \mathrm{C} 6$, and $\mathrm{C} 7$ dicarboxylic acids with oxygen-to-carbon ratios (O:C) of 0.80 , 0.67 , and 0.57 , respectively were investigated. AS has been chosen as the model inorganic salt due to its abundance in the atmosphere and its well-characterized thermodynamic and spectroscopic properties (Braban and Abbatt, 2004; Ling and Chan, 2008; Yeung et al., 2009). To explore the phase diagram, we mixed the components in different organic-toinorganic dry mass ratios (OIR). We use optical microscopy and micro-Raman spectroscopy to elucidate the phase transitions of these model systems when exposed to RH cycles. A main goal is to investigate the RH conditions and mixture compositions for which the model systems exhibit LLPS. The study of single particles allows for the investigations of miscibility gaps in solutions that are supersaturated with respect to a crystalline species and, hence, not directly accessible to bulk measurements. It also allows studying particle morphologies. Laboratory experiments of single aerosol particles are thus essential to improve our understanding of aerosol processes.

\section{Experimental and modelling methods}

\subsection{Materials}

Aqueous solutions containing different OIR of the three model systems were prepared by dissolving the pure substances in purified water (resistivity $\geq 18.0 \mathrm{M} \Omega \mathrm{cm}$ ). The mixture "C5" consists of three C5-dicarboxylic acids (glutaric, methylsuccinic, and dimethylmalonic acid), "C6" of three C6-dicarboxylic acids (2-methylglutaric, 3methylglutaric, and 2,2-dimethylsuccinic acid), and "C7" of three C7-dicarboxylic acids (3-methyladipic acid, 3,3dimethylglutaric acid and diethylmalonic acid), mixed together in equal mass (and molar) ratios. All components were purchased from Sigma-Aldrich with purities $\geq 98 \%$ and were used without further purification.

\subsection{Raman microscopy of single droplets}

Figure 1 shows schematically the experimental setup. Single droplets in a new custom-made cell are investigated with a Raman microscope (Jobin Yvon, model: Labram). Using a droplet generator (Knopf, 2003), micrometer-sized aqueous droplets were deposited on a glass cover slip $(\approx 15 \mathrm{~mm}$ diameter) that was hydrophobically coated by a silanization solution (Sigma-Aldrich) containing 5\% dimethyldichlorosilane in heptane to avoid heterogeneous nucleation due to surface contact. The coating procedure is described in detail in Knopf (2003). The cover slip was mounted in the

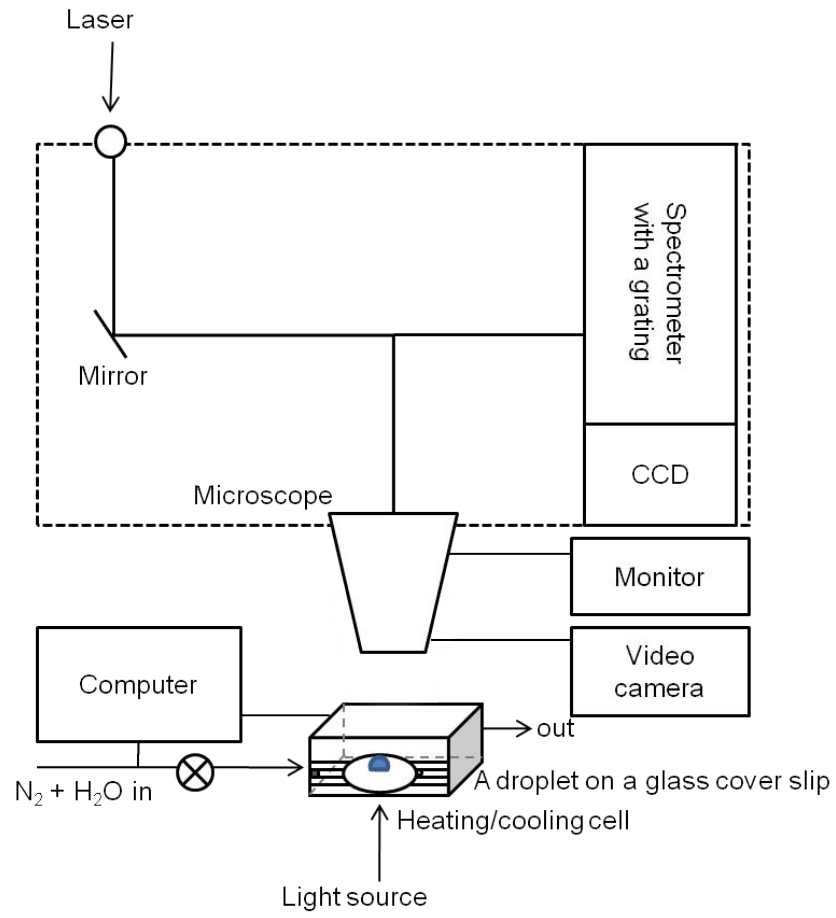

Fig. 1. Schematic representation of the experimental setup. A single particle (shown as blue half sphere) is deposited on a hydrophobically coated slide glass.

cell with inner dimension of $30 \mathrm{~mm}$ in diameter and $0.1-$ $0.2 \mathrm{~mm}$ in height. The cell is kept at constant temperature $\left(20^{\circ} \mathrm{C}\right)$ by water cooling/heating of the cell housing. $\mathrm{RH}$ is regulated by a $\mathrm{N}_{2} / \mathrm{H}_{2} \mathrm{O}$ flow that is brought to cell temperature before entering the cell. A single droplet on the cover slip was chosen and monitored with video microscopy during a humidity cycle. To change $\mathrm{RH}$, the water vapor mixing ratio of a constant total $\mathrm{N}_{2} / \mathrm{H}_{2} \mathrm{O}$ flow $(180 \mathrm{sccm})$ was varied by mixing dry and water-saturated $\mathrm{N}_{2}$ flows using automatic mass flow controllers. Temperature and $\mathrm{RH}$ of the gas flow inside the cell were measured by a G-TUCN.34 sensor (U.P.S.I., France; capacity probe for RH, NTC for $T$ ) which is positioned about $5 \mathrm{~mm}$ downstream from the gas entrance. During the experiments, the gas flow temperature was maintained at $20 \pm 0.2^{\circ} \mathrm{C}$. The cell temperature was also measured directly on the substrate by a Pt100 temperature sensor (Minco, USA). The deviation between the two sensors was less than $0.3^{\circ} \mathrm{C}$. Adjustment of the flows through the mass flow controllers, readout of the temperature and humidity and the synchronization with the video signal was controlled by a PC using custom software implemented in VEE (Agilent, USA). During humidity cycles, morphological changes of the droplet are monitored optically with the microscope equipped with a long working distance objective (Olympus BX-40, magnification 50, aperture 0.7). A black and white CCIR video camera with an acquisition frequency of 25 frames s$^{-1}$ was used to acquire images and movies of 
the droplet morphology. At the beginning of the experiment, the droplet was equilibrated at high RH $(\sim 95 \%)$. Humidity cycles comprise a $\mathrm{RH}$ reduction from 95 to $20 \%$ and subsequent increase from 20 to $95 \%$ at a rate of $0.1-$ $0.3 \% \mathrm{RH}_{\min }^{-1}$.

To identify the composition of the droplet phases, Raman spectra were acquired at constant RH and temperature conditions with the Raman system coupled to the optical microscope. A Nd:YAG (532 nm wavelength) laser operated at $75-100 \mathrm{~mW}$ power was used as the excitation source. An 1800 grooves $\mathrm{mm}^{-1}$ grating and a CCD camera were used to analyze the backscattered light from the sample. We obtained Raman spectra at different positions on the particles in the range of $150-4000 \mathrm{~cm}^{-1}$ with a spectral resolution of about $2-4 \mathrm{~cm}^{-1}$ and an integration time of $200 \mathrm{~s}$.

\subsection{RH and temperature sensor calibrations}

The specified accuracy of the G-TUCN.34 RH sensor by the manufacturer is $\pm 2 \%$ in the RH range from $2-98 \%$. However, we observed that this type of sensor might show offsets compared to the calibration curve provided by the company. Therefore, by measuring the DRH of various pure inorganic salts at room temperature, such as $\mathrm{KNO}_{3}(93.5 \%)$, $\left(\mathrm{NH}_{4}\right)_{2} \mathrm{SO}_{4}(80.0 \%), \mathrm{NaCl}(75.0 \%), \mathrm{NH}_{4} \mathrm{NO}_{3}(65.5 \%)$, $\mathrm{NaI}(38.0 \%)$ and $\mathrm{MgCl}_{2} \cdot 6 \mathrm{H}_{2} \mathrm{O}(33.0 \%)$, which cover a wide range of RH values, we recalibrated the G-TUCN.34 RH sensor. To do this, the RH in the cell was continuously increased at a rate of about $0.05 \% \mathrm{RH} \mathrm{min}^{-1}$ and the $\mathrm{RH}$ value at which onset of deliquescence was observed was registered as the DRH and compared with literature values. Each DRH value was determined using at least two independent particles in the diameter range of $10-35 \mu \mathrm{m}$. With this calibration, we obtained an accuracy of the humidity sensor of $\pm 1.5 \% \mathrm{RH}$. In order to detect sudden offsets of RH, the calibration was checked by a DRH experiment with a pure AS crystal every two weeks when experiments have been performed. We calibrated the temperature sensors by determining the melting point of ice particles using the same procedure as described in Knopf and Lopez (2009). Water droplets of $15-60 \mu \mathrm{m}$ in diameter froze at about $-35^{\circ} \mathrm{C}$ in the cell. Subsequently, the ice melting point was determined using a heating ramp of $0.03{ }^{\circ} \mathrm{C} \mathrm{min}^{-1}$. The temperature sensors proved to work accurately with deviations from the melting temperature of about $\pm 0.1^{\circ} \mathrm{C}$.

\subsection{Saturation solubility and water activity measurements}

To determine the physical properties of the dicarboxylic acids and AS, we measured their individual solubility in water and the water activity $\left(a_{\mathrm{w}}\right)$ of the saturated solutions. By stepwise adding small portions of water until the solute was completely dissolved, saturated aqueous solutions were prepared. The solutions were allowed to equilibrate in a ther- mostated water bath at $25.0 \pm 0.1{ }^{\circ} \mathrm{C}$ in between the additions. The estimated uncertainty of this procedure is less than $1.0 \mathrm{wt} \%$. The $a_{\mathrm{w}}$ of the saturated aqueous solutions were measured at $25^{\circ} \mathrm{C}$, using a water activity meter (AquaLab Model 3TE, Decagon Devices, USA). In order to correct for instrument offset and drift, the performance of the sample block was frequently controlled and readjusted with reference samples (Marcolli and Krieger, 2006). The experimental errors for the measurements with standard samples such as $\mathrm{KNO}_{3}\left(a_{\mathrm{w}}=0.925\right)$ and $\mathrm{NaCl}\left(a_{\mathrm{w}}=0.753\right)$ were $\pm 0.002 a_{\mathrm{w}}$ and $\pm 0.009 a_{\mathrm{w}}$, respectively.

\subsection{Thermodynamic modeling}

We use the method developed by Zuend et al. (2010) for the computation of LLPS in mixed organic/inorganic systems. This method is based on the global minimization of the Gibbs energy of a system to find the number of phases and corresponding compositions at thermodynamic equilibrium. In order to calculate the Gibbs energy at a given composition, activity coefficients of all components are required to account for non-ideal mixing. Following Zuend et al. (2010), we use the group-contribution model AIOMFAC developed by Zuend et al. (2008) with the new and extended set of organic/inorganic interaction parameters determined by Zuend et al. (2011). This recent implementation of the new AIOMFAC model parameters to describe interactions between various important organic functional groups and inorganic ions enables the computation of activity coefficients in multicomponent mixtures such as those investigated in this study.

Phase separation computations were performed at $298 \mathrm{~K}$ for the three 5-component systems $\mathrm{C} 5 / \mathrm{AS} / \mathrm{H}_{2} \mathrm{O}$, $\mathrm{C} 6 / \mathrm{AS} / \mathrm{H}_{2} \mathrm{O}$, and $\mathrm{C} 7 / \mathrm{AS} / \mathrm{H}_{2} \mathrm{O}$ with the components as given in Table 1. In addition, phase diagrams for three corresponding 3-component systems were computed, each containing only one of the dicarboxylic acids (one of the C5, C6, or C7 diacids used in the 5-component systems), $\mathrm{AS}$, and water. In contrast to a laboratory experiment, in a model calculation the potential crystallization of a single dicarboxylic acid in a mixture can be suppressed. Hence, the ternary systems allow a direct comparison with the results for the corresponding 5-component systems at the same dry (water-free) mass fractions of AS $\left(\mathrm{mf}_{\mathrm{d}}(\mathrm{AS})\right.$, $\mathrm{mf}_{\mathrm{d}}(\mathrm{AS})=\operatorname{mass}(\mathrm{AS}) /$ mass $($ organics + AS $\left.)\right)$. Such comparisons of the 5-component with 3-component systems allow an evaluation of the influence of using a mixture of three structural isomers for the organic fraction versus only one corresponding organic compound in AIOMFAC group-contribution model calculations. Furthermore, the ternary systems are of use as they allow a mathematically simpler computation of metastable and unstable regions of the phase diagram employing the algorithm of Zuend et al. (2010), as detailed in Sect. 3.5. In the calculations of the miscibility gap, the formation of crystalline AS at concentrations above its solubility limit was ignored, instead 
Table 1. Molecular weights (MW), aqueous solubility in weight percent at $25^{\circ} \mathrm{C}$, water activities $\left(a_{\mathrm{W}}\right)$ of saturated solutions at $25^{\circ} \mathrm{C}$, oxygen-to-carbon atomic ratios (O:C) and hydrogen-to-carbon atomic ratios (H:C) of investigated dicarboxylic acids and AS.

\begin{tabular}{lccccc}
\hline System components & $\begin{array}{c}\text { MW } \\
\left(\mathrm{g} \mathrm{mol}^{-1}\right)\end{array}$ & $\begin{array}{r}\text { Solubility } \\
(\mathrm{wt} \%)\end{array}$ & $\begin{array}{c}a_{\mathrm{w}} \text { of saturated } \\
\text { solution }\end{array}$ & O:C & H:C \\
\hline C5 & & & & & \\
\hline Glutaric acid & 132.12 & 58.8 & 0.883 & & \\
Methylsuccinic acid & 132.12 & 32.0 & 0.943 & 0.80 & 1.60 \\
Dimethylmalonic acid & 132.12 & 10.5 & 0.979 & & \\
\hline C6 & & & & & \\
\hline 2-methylglutaric acid & 146.14 & 52.7 & 0.929 & & \\
3-methylglutaric acid & 146.14 & 45.3 & 0.935 & 0.67 & 1.67 \\
2,2-dimethylsuccinic acid & 146.14 & 8.3 & 0.982 & & \\
\hline C7 & & & & & \\
\hline 3-methyladipic acid & 160.17 & 17.1 & 0.979 & & \\
3,3-dimethylglutaric acid & 160.17 & 14.2 & 0.982 & 0.57 & 1.71 \\
Diethylmalonic acid & 160.17 & 19.5 & 0.979 & & \\
\hline AS & 132.14 & 43.2 & 0.802 & & \\
\hline
\end{tabular}

all AS is kept in the liquid mixture, leading to supersaturated solutions at lower water contents, corresponding to the drying branch of the humidity cycles in the experiments, down to the efflorescence of AS.

\section{Results and discussion}

\subsection{Physical properties of the investigated mixtures}

Table 1 presents solubility and $a_{\mathrm{w}}$ of saturated solutions of the dicarboxylic acids at $25^{\circ} \mathrm{C}$. Despite their quite high solubility in water, $a_{\mathrm{w}}$ of the saturated solutions are high compared with values obtained for inorganic solutions of similar mass concentrations. This is due to the comparably high molecular weights of the dicarboxylic acids, their negligible degree of dissociation in solution together with only moderate hydrophilicity. The increasing hydrophobic nature with increasing carbon number is reflected by the oxygento-carbon atomic ratios (O:C), also given in Table 1, which decreases from the $\mathrm{C} 5$ to the $\mathrm{C} 7$ dicarboxylic acids from 0.80 to 0.57 . Instead of using one dicarboxylic acid, three acids of equal carbon number are mixed together in mixtures C5$\mathrm{C} 7$ to better mimic the effect of a complex mixture of compounds in the organic fraction of real aerosols, in which crystallization of organic components during humidity cycles is effectively suppressed due to the many components, as discussed in Marcolli et al. (2004). In this context, the straight chain $\mathrm{C} 6$ and $\mathrm{C} 7$ dicarboxylic acids (adipic and pimelic acid) were excluded from the mixtures because of their low aqueous solubility and related limited crystallization suppression of these dicarboxylic acids when the organic fraction is only represented by three compounds.
For the following experiments, a $\mathrm{C} 5$ mixture consisting of the three $\mathrm{C} 5$ components, a $\mathrm{C} 6$ and a $\mathrm{C} 7$ mixture were prepared. In a first step, single droplets of these purely organic mixtures were injected into the cell and investigated in the microscope. They remained as one liquid phase droplets down to dry RH conditions and did neither show LLPS nor efflorescence. In a second step, these three-component organic mixtures were mixed together with AS and water in different OIR and investigated as single droplets. The following section shows examples of time sequences for $\mathrm{OIR}=1: 1$. In Sect. 3.3 the chemical compositions of the observed phases are discussed. In Sects. 3.4 and 3.5, experimental and calculated phase diagrams are presented and discussed. Considerations of particle morphologies are given in Sect. 3.6.

\subsection{LLPS features of $\mathrm{C} 5 / \mathrm{AS} / \mathrm{H}_{2} \mathrm{O}, \mathrm{C} 6 / \mathrm{AS} / \mathrm{H}_{2} \mathrm{O}$ and $\mathrm{C} 7 / \mathrm{AS} / \mathrm{H}_{2} \mathrm{O}$ droplets}

Humidity cycles were performed with 4 droplets of $\mathrm{C} 5 / \mathrm{AS} / \mathrm{H}_{2} \mathrm{O}, 9$ droplets of $\mathrm{C} 6 / \mathrm{AS} / \mathrm{H}_{2} \mathrm{O}$, and 5 droplets of $\mathrm{C} 7 / \mathrm{AS} / \mathrm{H}_{2} \mathrm{O}$ all with $\mathrm{OIR}=1: 1$ and dry diameters in the range of 20-60 $\mu \mathrm{m}$. Figure 2 exemplifies the phase and morphological changes that were observed optically. At the beginning of the humidity cycles at high RH (set to time $t=0$ ), the droplets displayed only one liquid phase as shown in the first frames of Fig. 2a, b and c, taken at RH of $87 \%, 78 \%$ and $90 \%$, respectively.

The $\mathrm{C} 5 / \mathrm{AS} / \mathrm{H}_{2} \mathrm{O}$ droplet effloresced at $39.2 \% \mathrm{RH}(t=$ 138 min, Fig. 2a) upon drying without showing any evidence of precedent LLPS. This value is within the range of ERH of pure AS particles (e.g. Ciobanu et al., 2010). This together 

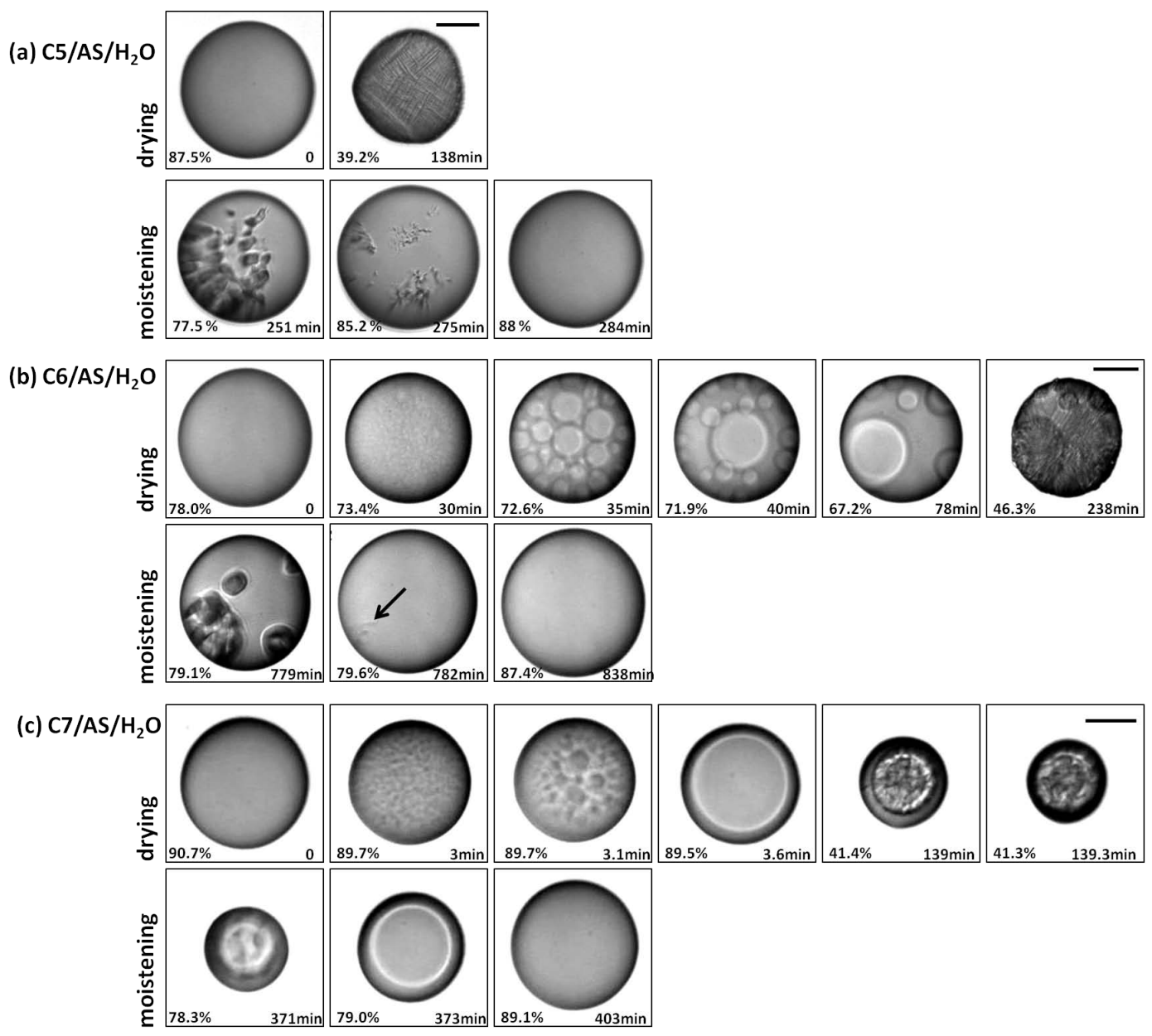

Fig. 2. Humidity cycles of (a) C5/AS/ $\mathrm{H}_{2} \mathrm{O}$ particle (top rows, $\mathrm{dRH} / \mathrm{d} t= \pm 0.33 \% \mathrm{~min}^{-1}$ ), (b) $\mathrm{C} 6 / \mathrm{AS} / \mathrm{H}_{2} \mathrm{O}$ particle (center rows, $\mathrm{dRH} / \mathrm{d} t=$ $\pm 0.14 \% \mathrm{~min}^{-1}$ ), and (c) $\mathrm{C} 7 / \mathrm{AS} / \mathrm{H}_{2} \mathrm{O}$ particle (bottom rows, $\mathrm{dRH} / \mathrm{d} t= \pm 0.34 \% \mathrm{~min}^{-1}$ ) all with OIR $=1: 1$. At time $t=0$, all particles are present as droplets with a single liquid phase. Size bar: $20 \mu \mathrm{m}$.

with the finding that pure $\mathrm{C} 5 / \mathrm{H}_{2} \mathrm{O}$ (AS-free) droplets did not effloresce during humidity cycles down to $20 \% \mathrm{RH}$ indicates that nucleation of AS initiated the efflorescence process. Upon subsequent moistening, the effloresced particle gradually absorbed water, followed by sudden dissolution of most solid material at $\approx 77.5 \% \mathrm{RH}(t=251 \mathrm{~min})$. Some crystals remained up to $\approx 85.2 \% \mathrm{RH}$, when discernible dissolution again set in $(t=275 \mathrm{~min})$. This high DRH cannot be ascribed to the deliquescence of AS and shows that at least a part of the C5 dicarboxylic acids crystallized, probably by heterogeneous nucleation on AS crystals. To ascertain the dissolution order of the substances, we also conducted a bulk measurement at $20^{\circ} \mathrm{C}$ by adding water stepwise to the crystalline C5/AS mixture until a clear solution was obtained. We observed by eyes that the AS crystals were completely dissolved at $a_{\mathrm{w}}=0.79 \pm 0.004$ with the glutaric and methylsuccinic acids. Therefore, it indicates that AS in C5/AS/ $\mathrm{H}_{2} \mathrm{O}$ deliquesced at between $77.5 \%$ and $79.0 \% \mathrm{RH}$.
LLPS was observed for the $\mathrm{C} 6 / \mathrm{AS} / \mathrm{H}_{2} \mathrm{O}$ droplet by the abrupt appearance of schlieren at $73.4 \% \mathrm{RH}(t=30 \mathrm{~min}$, Fig. 2b) upon water evaporation. Such schlieren (Kostorz, 2001), which appear as small separated regions all over a droplet are involved in spinodal decomposition. The schlieren developed into small droplets that coalesced to form an inner phase within the particle. Ciobanu et al. (2009) have also observed spinodal decomposition for LLPS of PEG-400/AS/ $\mathrm{H}_{2} \mathrm{O}$ particles. At $71.9 \% \mathrm{RH}$, inner and outer phases together with satellite inclusions can be clearly discriminated in the liquid droplet. Interestingly, after LLPS had occurred, the inner phase that was confirmed to consist of aqueous AS by Raman spectroscopy (see Sect. 3.3) tended to move from the core toward the edge of the particle as more water was released. This partially engulfed configuration can be seen at $67.2 \%$ RH in Fig. 2b. Such particle morphology has recently been postulated by Kwamena et al. (2010) and Reid et al. (2011). A further decrease in RH leads to efflorescence and crystal growth in both phases of the particle 


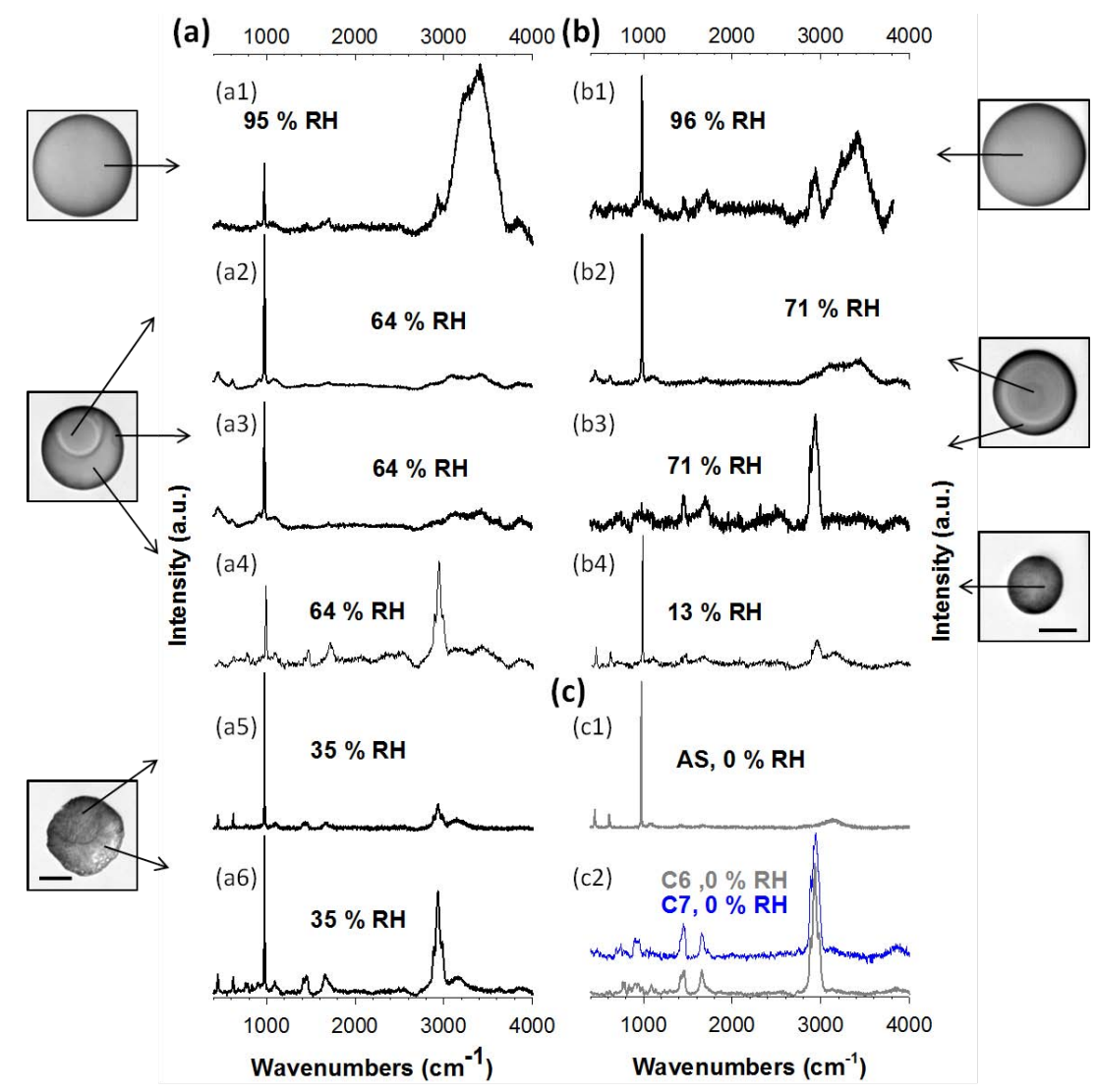

Fig. 3. Raman spectra and microscopic images of (a) C6/AS/ $\mathrm{H}_{2} \mathrm{O}$ and (b) $\mathrm{C} 7 / \mathrm{AS} / \mathrm{H}_{2} \mathrm{O}$ particles with $\mathrm{OIR}=1: 1$ at different $\mathrm{RH}$. Reference spectra are included for AS (c1) and for the pure C6 and C7 organic mixtures (c2). Size bars in the microscopic images are $20 \mu \mathrm{m}$.

at $46.3 \%$ ( $t=238 \mathrm{~min})$. This value is above the typical range observed for ERH of pure AS droplets (e.g. Ciobanu et al., 2010) and will be discussed in more detail in Sect. 3.4. For subsequently increasing RH, the crystals in the outer phase deliquesced first, followed by fast dissolution of the solid material in the inner phase at $79.1 \% \mathrm{RH}$. When AS had deliquesced at $79.6 \% \mathrm{RH}$, a remnant of crystallized organic material, most likely 2,2-dimethylsuccinic acid (considering results of bulk measurement using the same method as for the C5/AS) remains (marked by an arrow on Fig. 2b, $t=782 \mathrm{~min}$ ). The particle fully deliquesced as one liquid phase at $87.4 \% \mathrm{RH}$.

In the $\mathrm{C} 7 / \mathrm{AS} / \mathrm{H}_{2} \mathrm{O}$ droplet shown in Fig. 2c, LLPS was induced by spinodal decomposition at $\mathrm{RH}$ as high as $90 \%$ $(t=3 \mathrm{~min})$ when the humidity was decreased. Schlieren formation and coalescence can be seen at almost the same RH ( $t=3 \mathrm{~min}$ and $3.1 \mathrm{~min}$ in Fig. 2c) leading to a coreshell morphology without satellite inclusions in the outer phase at $t=3.6 \mathrm{~min}$. It is interesting to note that the coreshell or completely engulfed morphology is the main configuration in the $\mathrm{C} 7 / \mathrm{AS} / \mathrm{H}_{2} \mathrm{O}$ particle for OIR $=1: 1$ while for $\mathrm{C} 6 / \mathrm{AS} / \mathrm{H}_{2} \mathrm{O}$ droplets the partially engulfed morphology prevailed. A gradual loss of water resulted in a shrinkage of the particle until the inner phase effloresced at $41.4 \% \mathrm{RH}$.
The outer phase that was confirmed to consist mainly of organics (see Sect. 3.3) did not seem to crystallize, probably because the very low AS concentration or a high viscosity in this phase derates crystal growth. Rather, it was sucked into cavities of the crystalline inner phase within a few seconds $(t=139.3 \mathrm{~min})$ most probably because of capillary forces (Sjogren et al., 2007). Undergoing water uptake, the particle deliquesced and returned into a two-liquid-phases state at $79 \% \mathrm{RH}$. In contrast to the $\mathrm{C} 6 / \mathrm{AS} / \mathrm{H}_{2} \mathrm{O}$ particle (Fig. $2 \mathrm{~b}$, $t=782 \mathrm{~min}$ ), the $\mathrm{C} 7 / \mathrm{AS} / \mathrm{H}_{2} \mathrm{O}$ particle shows no remaining solid above the DRH of AS. The two liquid phases merged into one liquid phase at $89.1 \% \mathrm{RH}$.

\subsection{Chemical compositions of the different phases}

To identify the chemical composition of the different phases present in $\mathrm{C} 6 / \mathrm{AS} / \mathrm{H}_{2} \mathrm{O}$ and $\mathrm{C} 7 / \mathrm{AS} / \mathrm{H}_{2} \mathrm{O}$ particles which have shown LLPS, we collected Raman spectra at constant RH on particles with OIR $=1: 1$. Figure 3 depicts representative Raman spectra collected at different positions as indicated in the optical images of the particles. Spectra of an AS crystal (Fig. 3, c1) and a liquid droplet of purely organic 3-components $\mathrm{C} 6$ and $\mathrm{C} 7$ mixtures at $\mathrm{RH}=0 \%$ are also included as references (Fig. 3, c2). The most prominent feature 
in the reference spectrum of crystalline AS is the symmetric stretching vibration of $\mathrm{SO}_{4}^{2-}$ at $\sim 975 \mathrm{~cm}^{-1}$ (Zhang and Chan, 2002; Ling and Chan, 2008; Ciobanu et al., 2009). The band of the stretching vibration of $\mathrm{NH}_{4}^{+}$at around $3130 \mathrm{~cm}^{-1}$ (Ciobanu et al., 2009; Yeung et al., 2009) is also distinguished. The $\mathrm{C} 6$ and $\mathrm{C} 7$ references reveal $\mathrm{C}-\mathrm{H}$ stretching vibrations at $2880-2984$ and $2875-2990 \mathrm{~cm}^{-1}$, respectively, and several peaks between 700 and $1670 \mathrm{~cm}^{-1}$. The $\mathrm{C}=\mathrm{O}$ stretching vibrations appear as relatively sharp peaks at $\sim 1656 \mathrm{~cm}^{-1}$ for the $\mathrm{C} 6$ and at $\sim 1658 \mathrm{~cm}^{-1}$ for $\mathrm{C} 7$ mixtures.

In the one-liquid-phase state of $\mathrm{C} 6 / \mathrm{AS} / \mathrm{H}_{2} \mathrm{O}$ and C7/AS/ $\mathrm{H}_{2} \mathrm{O}$ droplets, the sharp peak at $\sim 980 \mathrm{~cm}^{-1}$ and the broad band between 2870 and $3000 \mathrm{~cm}^{-1}$, originating from AS and dicarboxylic acids, respectively (a1 and b1 of Fig. 3), are clearly visible. In addition, at this high $\mathrm{RH}$, symmetric and antisymmetric $\mathrm{O}-\mathrm{H}$ stretching modes of water molecules can be detected as an additional intense broad band in the range of $3030-3700 \mathrm{~cm}^{-1}$ (Yeung et al., 2009). This is clear evidence for the presence of both AS and organics in one aqueous phase.

At $64 \% \mathrm{RH}$, when the $\mathrm{C} 6 / \mathrm{AS} / \mathrm{H}_{2} \mathrm{O}$ droplet is in the twoliquid-phases state, Raman spectra were collected from the satellite inclusions, the inner phase and the outer phase. As shown by the dominance of the AS peak at $979 \mathrm{~cm}^{-1}$, the low intensity of the water band and the hardly visible spectral features of the dicarboxylic acids in spectra (a2) and (a3) of Fig. 3a, the inner phase and the satellite inclusions consist of a concentrated aqueous AS solution containing only small amounts of organics. On the other hand, spectrum (a4) acquired from the outer phase of $\mathrm{C} 6 / \mathrm{AS} / \mathrm{H}_{2} \mathrm{O}$ shows well discernable signals of the dicarboxylic acids and the AS and water bands appear only as weak features, establishing the outer phase as highly concentrated aqueous dicarboxylic acid solution with AS as a minor component (see also Ciobanu et al., 2009; Smith et al., 2011).

Raman spectra of the outer and the inner phases of the $\mathrm{C} 7 / \mathrm{AS} / \mathrm{H}_{2} \mathrm{O}$ droplet measured at $71 \% \mathrm{RH}$ give evidence of an almost complete phase separation: the dicarboxylic acid peaks are hardly visible in the Raman spectrum of the inner aqueous AS phase (b2 of Fig. 3b) and the main AS peak at $979 \mathrm{~cm}^{-1}$ is very weak in the Raman spectrum of the outer organic-rich phase (b3). Also, the spectral signature of the water band can be hardly detected in the organic-rich phase indicating its low water content. More complete phase separation in the $\mathrm{C} 7 / \mathrm{AS} / \mathrm{H}_{2} \mathrm{O}$ system than in the $\mathrm{C} 6 / \mathrm{AS} / \mathrm{H}_{2} \mathrm{O}$ system is expected because of the more hydrophobic nature (lower O:C) of the C7 compared with the C6 dicarboxylic acids.

Spectra of the effloresced particles were collected at $35 \%$ and $13 \% \mathrm{RH}$ for the $\mathrm{C} 6 / \mathrm{AS} / \mathrm{H}_{2} \mathrm{O}$ and the $\mathrm{C} 7 / \mathrm{AS} / \mathrm{H}_{2} \mathrm{O}$ droplets, respectively. For both systems efflorescence of the AS component is confirmed by the increased sharpness of the peaks at 451 and $614 \mathrm{~cm}^{-1}$ and the shift of the main peak from $\sim 979$ to $\sim 975 \mathrm{~cm}^{-1}$. Such effects due to the crystallization of AS have been described by Zhang and
Chan (2002) and Ciobanu et al. (2009). The Raman spectra do not provide any clear evidence of the phase state of the dicarboxylic acids. The distribution of the two liquid phases within the droplet is mostly conserved during efflorescence as can be seen optically and from comparison of the Raman spectra (c1) and (c2) of Fig. 3c: the effloresced inner phase is enriched in crystalline AS compared with the outer phase. Nevertheless, a certain remixing of the phases takes place after efflorescence, as can be clearly seen from the increased intensity of the dicarboxylic acid spectral features in the inner phase of the $\mathrm{C} 6 / \mathrm{AS} / \mathrm{H}_{2} \mathrm{O}$ droplet after efflorescence (spectrum (a5) compared with (a2)) and in the inner phase of the $\mathrm{C} 7 / \mathrm{AS} / \mathrm{H}_{2} \mathrm{O}$ droplet (spectrum (b4) compared with (b2)). We assume that this remixing is driven by capillary forces that act in veins of polycrystalline AS and cavities between AS needles.

\subsection{Phase diagrams of $\mathrm{C} 6 / \mathrm{AS} / \mathrm{H}_{2} \mathrm{O}$ and $\mathrm{C} 7 / \mathrm{AS} / \mathrm{H}_{2} \mathrm{O}$ systems}

To fully assess the dependence of LLPS on mixing ratio and $\mathrm{RH}$ and to establish corresponding phase diagrams, $\mathrm{C} 5 / \mathrm{AS} / \mathrm{H}_{2} \mathrm{O}, \mathrm{C} 6 / \mathrm{AS} / \mathrm{H}_{2} \mathrm{O}$ and $\mathrm{C} 7 / \mathrm{AS} / \mathrm{H}_{2} \mathrm{O}$ particles with different OIR were investigated at $20^{\circ} \mathrm{C}$. We performed small humidity cycles (from 95 to 60 to $95 \%$ ) to determine whether there is a hysteresis between the onset of LLPS upon drying and the merging of the two liquid phases upon moistening, and large humidity cycles (from 95 to 20 to $95 \%$ ) to observe efflorescence and deliquescence processes. Typically, a small humidity cycle was followed by a large one. For some particles, we performed one to several large humidity cycles. The sizes of the investigated droplets were in the range from 24-75 $\mu \mathrm{m}$ diameters.

In the $\mathrm{C} 5 / \mathrm{AS} / \mathrm{H}_{2} \mathrm{O}$ particles LLPS did not occur for the investigated $\mathrm{OIR}=2: 1,1: 1$ and $1: 4$, instead, efflorescence occurred at $32.4 \%, 37.9 \%$, and $40.8 \% \mathrm{RH}$, for OIR $=2: 1$, $1: 1$, and $1: 4$, respectively. If LLPS occurred in this system, it would be at RH $<$ ERH. However, LLPS appeared in both $\mathrm{C} 6 / \mathrm{AS} / \mathrm{H}_{2} \mathrm{O}$ and $\mathrm{C} 7 / \mathrm{AS} / \mathrm{H}_{2} \mathrm{O}$ systems over a broad composition range. Figure 4 presents phase diagrams of (a) $\mathrm{C} 6 / \mathrm{AS} / \mathrm{H}_{2} \mathrm{O}$ and (b) $\mathrm{C} 7 / \mathrm{AS} / \mathrm{H}_{2} \mathrm{O}$ systems as a function of $\mathrm{RH}$ in terms of $\mathrm{mf}_{\mathrm{d}}(\mathrm{AS})$ (lower $\mathrm{x}$-axis) and OIR (upper $\mathrm{x}$-axis).

In $\mathrm{C} 6 / \mathrm{AS} / \mathrm{H}_{2} \mathrm{O}$ particles LLPS occurred upon drying for $\mathrm{mf}_{\mathrm{d}}(\mathrm{AS})$ of $0.07-0.89$. Humidity cycles performed between $95 \%$ and $60 \%$ RH show no discernable hysteresis between onset and end of LLPS, i.e. the open and filled black circles in both Figs. 4a and $\mathrm{b}$ coincide within experimental uncertainties. The experiment carried out at $\mathrm{mf}_{\mathrm{d}}(\mathrm{AS})=0.92 \mathrm{did}$ not show any discernable LLPS, marking the end of the miscibility gap to high AS concentrations, though we cannot exclude the possibility that separation occurred but could not be detected because of lack of contrast. For $\mathrm{mf}_{\mathrm{d}}(\mathrm{AS})=0.30$ 0.89 the onset and end of LLPS is in the narrow range from $72-74 \%$ RH. On the other hand, in $\mathrm{C} 7 / \mathrm{AS} / \mathrm{H}_{2} \mathrm{O}$ particles 

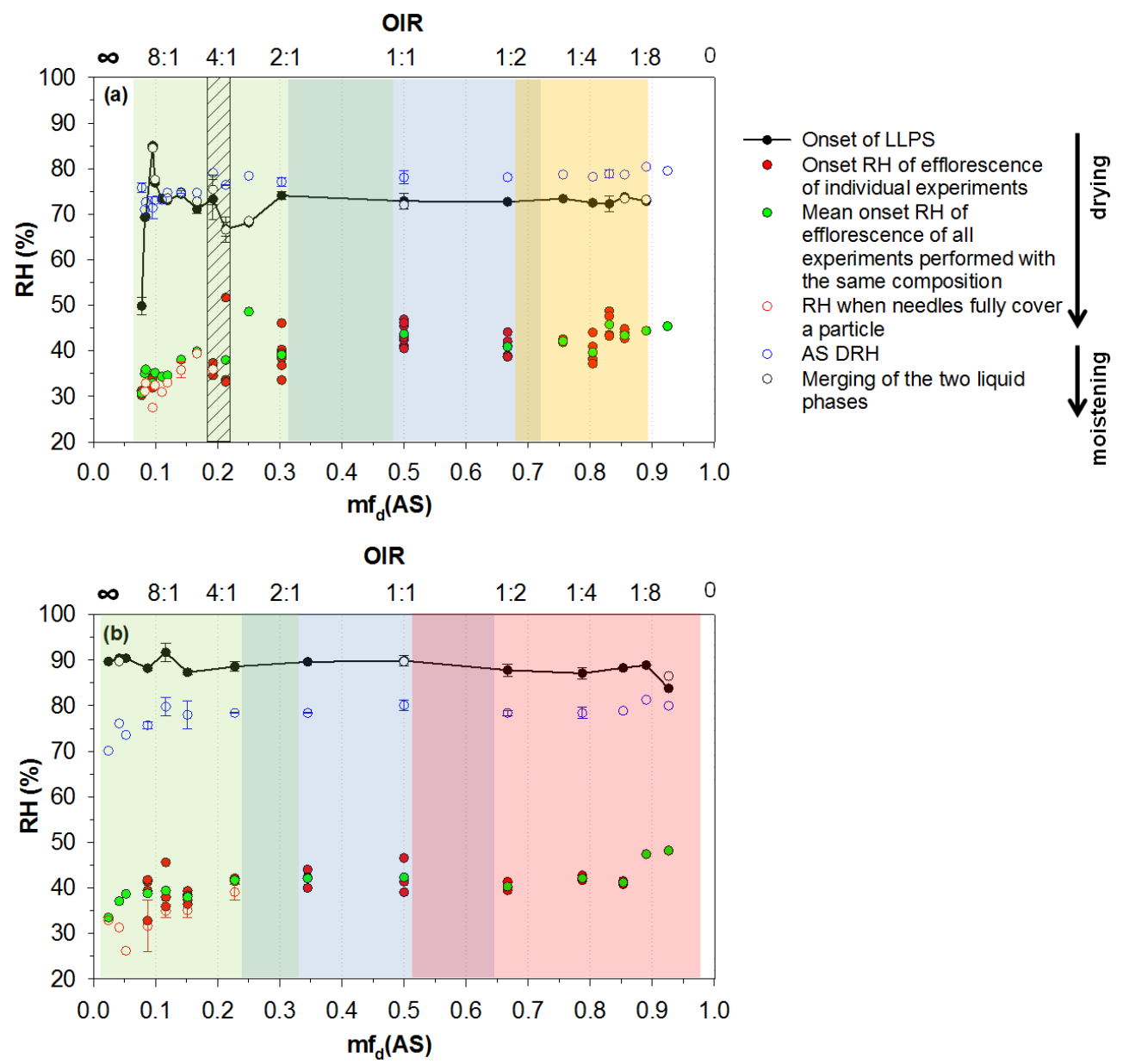

Fig. 4. Phase diagrams of (a) $\mathrm{C} 6 / \mathrm{AS} / \mathrm{H}_{2} \mathrm{O}$ and (b) $\mathrm{C} 7 / \mathrm{AS} / \mathrm{H}_{2} \mathrm{O}$ from humidity cycles. Black filled circles: LLPS onset. Red filled circles: efflorescence onset (mean values in green). Red open circles: completion of efflorescence. Blue open circles: AS deliquescence upon moistening. Black open circles: merging of the two liquid phases upon moistening. Background shadings represent different LLPS mechanisms upon drying: nucleation-and-growth (green), spinodal decomposition (blue), growth of a second phase at the surface of the particle (pink) and mechanism unclear (orange). Hatched area in (a): inconstant LLPS varying among different particles in the range of $0.19<\mathrm{mf}_{\mathrm{d}}(\mathrm{AS})<0.21$. Error bars: standard deviation of experiments with different particles.

we observed LLPS over the whole investigated composition range with onset values between 84-92\% RH upon drying and end values between 86-90\% RH during moistening, i.e. with no discernable hysteresis (Fig. 4b). The larger miscibility gap of the C7/AS/ $\mathrm{H}_{2} \mathrm{O}$ compared with the $\mathrm{C} 6 / \mathrm{AS} / \mathrm{H}_{2} \mathrm{O}$ system in terms of composition and $\mathrm{RH}$ range is consistent with the more hydrophobic character of the $\mathrm{C} 7$ compared with the C6 dicarboxylic acids.

A further decrease in RH leads to efflorescence of the particles. In Fig. 4a and $\mathrm{b}$ the average ERH of all experiments carried out with the same composition are shown as green filled circles, ERH of individual crystallization events as red filled circles. Open red circles show cases when crystal growth was very slow and mark the state with full needle coverage (this $\mathrm{RH}$ value depends on the rate at which particles were dried). The ERH scatters between individ- ual experiments because nucleation is a stochastic process (Martin, 2000) while the instrumental uncertainty is smaller than this scatter by factors 3 to 4 . In general, ERH decreases as AS concentrations decrease. For $\mathrm{mf}_{\mathrm{d}}(\mathrm{AS}) \geq 0.5$, ERH values range from $35-48 \% \mathrm{RH}$ for the $\mathrm{C} 6 / \mathrm{AS} / \mathrm{H}_{2} \mathrm{O}$ system and between $36-48 \% \mathrm{RH}$ for the $\mathrm{C} 7 / \mathrm{AS} / \mathrm{H}_{2} \mathrm{O}$ system as well. These ranges are at the high end or above ERH observed for other dicarboxylic acid/AS/ $\mathrm{H}_{2} \mathrm{O}$ systems: e.g. Parsons et al. (2004) and Zardini et al. (2008) report ERH for malonic acid/AS, glutaric acid/AS, and citric acid/AS particles consistently below $40 \%$. A possible explanation for the high ERH values observed in this study might be an increase of the ion activity coefficients due to the energetically disadvantageous interactions between the ions of AS and the C6 and C7 dicarboxylic acids, enhancing the probability for the formation of stable AS crystal nuclei at higher RH as 


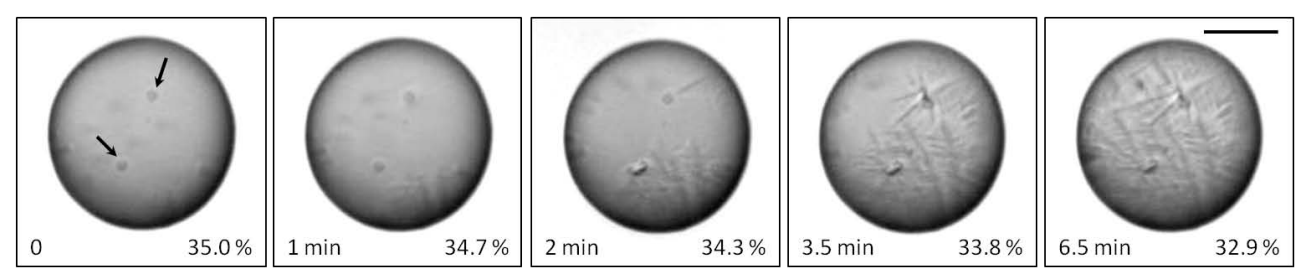

Fig. 5. Efflorescence process of a $\mathrm{C} 6 / \mathrm{AS} / \mathrm{H}_{2} \mathrm{O}$ particle with $\mathrm{mf}_{\mathrm{d}}(\mathrm{AS})=0.083(\mathrm{OIR}=11: 1)$ from onset of efflorescence at $35.0 \%$ until the particle is fully covered by needles at $32.9 \%$ RH. Size bar: $20 \mu \mathrm{m}$. Aqueous AS inclusions are marked by arrows.

compared to mixtures with the more hydrophilic malonic (C3 dicarboxylic acid), glutaric (C5 dicarboxylic acid) and citric acids.

Figure 5 illustrates nucleation and crystal growth of AS for a $\mathrm{C} 6 / \mathrm{AS} / \mathrm{H}_{2} \mathrm{O}$ particle with $\mathrm{OIR}=11: 1$. The main phase of this particle is organic-rich. Aqueous AS inclusions are marked by arrows. Crystallization started from the rim of the particle at $35 \% \mathrm{RH}$ and slowly proceeded until after $6.5 \mathrm{~min}$ the particle was fully covered with needles. Because our experiments were carried out at constant drying rate, this translates to a crystal growth that occurs over several percent in $\mathrm{RH}$ until a droplet is fully covered by needles as indicated in Fig. 4 (open red circles). The needles mostly consist of AS because they deliquesce at around the DRH of AS (open blue circles in Fig. 4). The aqueous AS inclusions crystallized when the AS needle had reached them. We attribute the slow crystal growth to the high viscosity that is reached in the organic-rich phase.

Upon increasing $\mathrm{RH}$, deliquescence of AS occurred between 70-80\% RH for both systems over the whole composition range. This is in good agreement with previous work (Braban and Abbatt, 2004; Parsons et al., 2004; Sjogren et al., 2007; Ling and Chan 2008; Smith et al., 2011). Upon moistening, the $\mathrm{C} 6 / \mathrm{AS} / \mathrm{H}_{2} \mathrm{O}$ and $\mathrm{C} 7 / \mathrm{AS} / \mathrm{H}_{2} \mathrm{O}$ particles showed noticeably different behavior. Whereas $\mathrm{C} 6 / \mathrm{AS} / \mathrm{H}_{2} \mathrm{O}$ particles returned into a one-liquid phase state upon deliquescence of AS, a two-liquid-phases state was restored when AS deliquesces in $\mathrm{C} 7 / \mathrm{AS} / \mathrm{H}_{2} \mathrm{O}$ particles. The reason for this different behavior is that for $\mathrm{C} 7 / \mathrm{AS} / \mathrm{H}_{2} \mathrm{O}$ the miscibility gap extends to $\mathrm{RH}>\mathrm{AS}$ DRH while the miscibility gap of $\mathrm{C} 6 / \mathrm{AS} / \mathrm{H}_{2} \mathrm{O}$ is restricted to compositions that are supersaturated with respect to AS and therefore ends at $\mathrm{RH}<\mathrm{AS}$ DRH.

In the $\mathrm{C} 6$ system, the situation is intricate at low AS concentration. LLPS was clearly visible for $\mathrm{mf}_{\mathrm{d}}(\mathrm{AS}) \approx 0.1$. In this concentration range, the highest observed onset of LLPS occurred (at RH $\approx 85 \% \mathrm{RH}$ for $\mathrm{mf}_{\mathrm{d}}(\mathrm{AS})=0.095$, OIR $=9.5: 1$ ). For $\mathrm{mf}_{\mathrm{d}}(\mathrm{AS})=0.08$, LLPS drops to $50 \% \mathrm{RH}$ marking the end of the miscibility gap to low AS concentrations. Surprisingly, for $\mathrm{mf}_{\mathrm{d}}(\mathrm{AS})=0.19$ and 0.21 (hatched area in Fig. 4a) LLPS was only detectable in 7 out of 12 and 7 out of 9 experiments, respectively. In cases with detectable LLPS, the onset RH scattered over quite a large $\mathrm{RH}$ range of
65-78\%. Interestingly, this large range cannot be explained by kinetically limited nucleation of the minor phase because no phase separation hysteresis could be observed when exposing the same particle to humidity cycles. Some particles showed reproducible LLPS during several humidity cycles while LLPS was reproducibly absent in others.

In order to clarify LLPS at high OIR in the $\mathrm{C} 6 / \mathrm{AS} / \mathrm{H}_{2} \mathrm{O}$ system, we collected Raman spectra of the $\mathrm{C} 6 / \mathrm{AS} / \mathrm{H}_{2} \mathrm{O}$ and the $\mathrm{C} 7 / \mathrm{AS} / \mathrm{H}_{2} \mathrm{O}$ systems in the one-liquid-phase state and in the organic-rich phase of the phase separated system for different $\mathrm{mf}_{\mathrm{d}}(\mathrm{AS})$, see Fig. 6 . From theory, we expect that mixtures with OIR within the miscibility gap partition into an organic-rich and an aqueous AS phase with constant compositions corresponding to the ones of the limits of the miscibility gap, irrespective of their OIR. This should be strictly true for systems measured at the same RH. The organicrich phase (given by the red circles in Fig. 6) should therefore exhibit a constant dicarboxylic acid/AS Raman peak ratio irrespective of the OIR. By comparing the Raman peak height ratios of the organic-rich phase with the ones in the one-liquid-phase state, it is furthermore possible to estimate the AS concentration of the organic-rich phase. To do this, we use the C6 $\left(2931 \mathrm{~cm}^{-1}\right) /$ AS $\left(979 \mathrm{~cm}^{-1}\right)$ and the C7 $\left(2937 \mathrm{~cm}^{-1}\right) / \mathrm{AS}\left(979 \mathrm{~cm}^{-1}\right)$ Raman peak height ratios of the one-liquid-phase states (at $85 \%$ and $95 \% \mathrm{RH}$ for the $\mathrm{C} 6 / \mathrm{AS} / \mathrm{H}_{2} \mathrm{O}$ and $\mathrm{C} 7 / \mathrm{AS} / \mathrm{H}_{2} \mathrm{O}$ systems, respectively) as a measure of AS concentration given as $\mathrm{mf}_{\mathrm{d}}(\mathrm{AS})$ on the $\mathrm{x}$-axis of Fig. 6. From this, we deduce an estimate of the AS concentration in the organic-rich phase in the phase separated system at $\mathrm{RH}=65 \%$. Figure $6 \mathrm{~b}$ shows a constant C7/AS ratio of $\sim 15$ corresponding to $\mathrm{mf}_{\mathrm{d}}(\mathrm{AS})$ well below 0.1 for the organic-rich phase of the $\mathrm{C} 7 / \mathrm{AS} / \mathrm{H}_{2} \mathrm{O}$ system - as expected from theory. The organic-rich phase of the $\mathrm{C} 6 / \mathrm{AS} / \mathrm{H}_{2} \mathrm{O}$ system exhibits a C6/AS ratio of $\sim 1$ that corresponds to $\mathrm{mf}_{\mathrm{d}}(\mathrm{AS}) \sim 0.3$ for overall compositions of $\mathrm{mf}_{\mathrm{d}}(\mathrm{AS})=0.50$ and 0.67 (Fig. 6a). This implies that the miscibility gap of this system is less complete than the one of the C $7 / \mathrm{AS} / \mathrm{H}_{2} \mathrm{O}$ system and should end at $\mathrm{mf}_{\mathrm{d}}(\mathrm{AS}) \sim 0.3$. However, the observed phase separation persists to lower $\mathrm{mf}_{\mathrm{d}}(\mathrm{AS})$, and, in addition, the AS content of the organic-rich phase is no longer a constant but decreases with decreasing $\mathrm{mf}_{\mathrm{d}}(\mathrm{AS})$ of the particle (corresponding to an increase of the C6/AS ratio up to $\sim 8$ for an overall $\mathrm{mf}_{\mathrm{d}}(\mathrm{AS})$ of 0.08 ). This implicates 

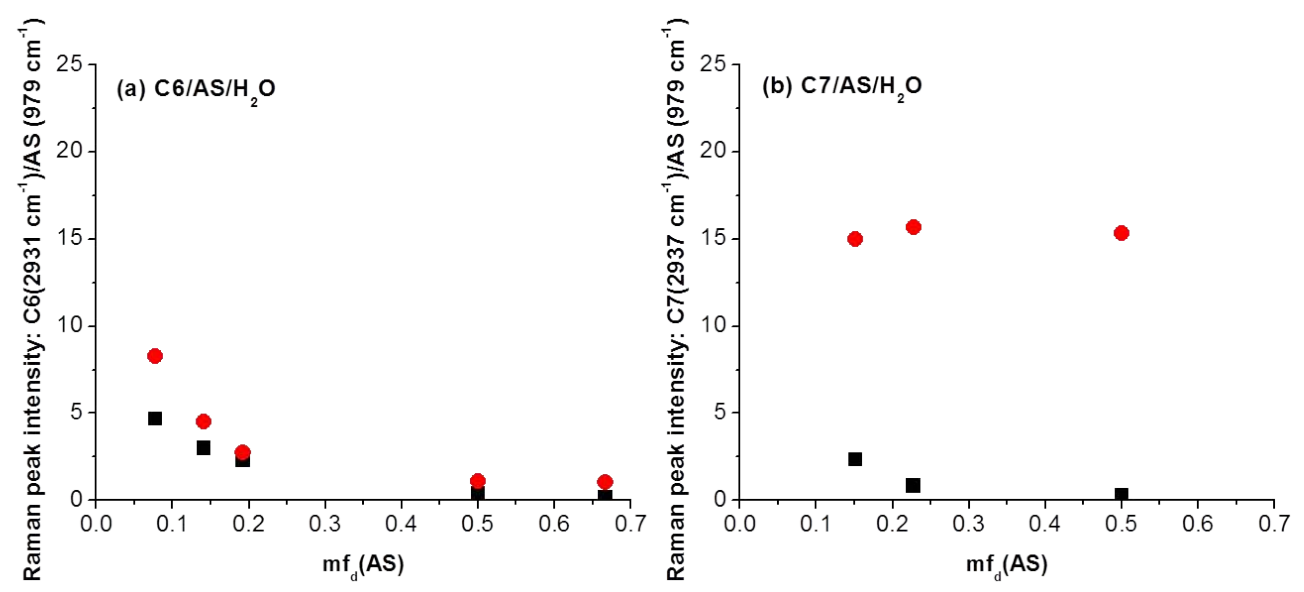

Fig. 6. (a) Ratios of C6 $\left(2931 \mathrm{~cm}^{-1}\right)$ to AS $\left(979 \mathrm{~cm}^{-1}\right)$ Raman peak intensities of a C6/AS/ $\mathrm{H}_{2} \mathrm{O}$ particle in the one-liquid-phase state at $\mathrm{RH}=85 \%$ (black squares) and of the organic-rich phase in the two-liquid-phases state at $\mathrm{RH}=65 \%$ (red circles), and (b) ratios of $\mathrm{C} 7$ $\left(2937 \mathrm{~cm}^{-1}\right)$ to AS $\left(979 \mathrm{~cm}^{-1}\right)$ Raman peak intensities of a C7/AS/ $\mathrm{H}_{2} \mathrm{O}$ particle in the one-liquid-phase state at $\mathrm{RH}=95 \%$ (black squares) and of the organic-rich phase in the two-liquid-phases state at $\mathrm{RH}=65 \%$ (red circles) as a function of the overall $\mathrm{mf}_{\mathrm{d}}(\mathrm{AS})$.

that $\mathrm{C} 6 / \mathrm{AS} / \mathrm{H}_{2} \mathrm{O}$ systems with $\mathrm{mf}_{\mathrm{d}}(\mathrm{AS})$ below 0.3 do not exhibit a typical LLPS. This issue will be discussed in detail in Sect. 3.5.

Ciobanu et al. (2009) found that LLPS may occur by spinodal decomposition, nucleation-and-growth, and growth of a second phase at the surface of the particle depending on OIR within internally mixed PEG-400/AS/ $\mathrm{H}_{2} \mathrm{O}$ particles. Nucleation-and-growth typically occurs in the metastable region of the phase diagram and is associated with overcoming an energy barrier to form stable nuclei of the second phase while spinodal decomposition occurs without a nucleation energy barrier at the border to the unstable region of the phase diagram (Shelby, 1995; Papon et al., 1999). To determine the different LLPS mechanisms from the microscopic images, we used the same methods as described by Ciobanu et al. (2009), which rely on the analysis of droplet morphology at the onset of phase separation and the evaluation of the number of AS inclusions as a function of time. Such assignment of phase separation mechanism is always prone to uncertainties because the very first stages of LLPS are not visible in optical microscopes due to limitations in spatial resolution and optical contrast. Given these limitations, in the $\mathrm{C} 6 / \mathrm{AS} / \mathrm{H}_{2} \mathrm{O}$ systems, LLPS occurring at $0.07<\mathrm{mf}_{\mathrm{d}}(\mathrm{AS})<0.40$ matched best with a nucleation-andgrowth mechanism whereas spinodal decomposition seemed to occur for $0.40<\mathrm{mf}_{\mathrm{d}}$ (AS) $<0.70$ (Fig. 4a). However, we were not able to determine the separation mechanism for LLPS occurring at $0.70<\mathrm{mf}_{\mathrm{d}}(\mathrm{AS})<0.89$ in the $\mathrm{C} 6 / \mathrm{AS} / \mathrm{H}_{2} \mathrm{O}$ systems (Fig. 4a) because the very first instances of phase separation are not clearly discernable due to lack of optical contrast. Figure 7a shows as an example for this case a time sequence of a droplet with OIR $=1: 4$. This droplet remained very dynamic with continuous appearance and coalescence of inclusions for a time period over $30 \mathrm{~min}$ (corresponding to

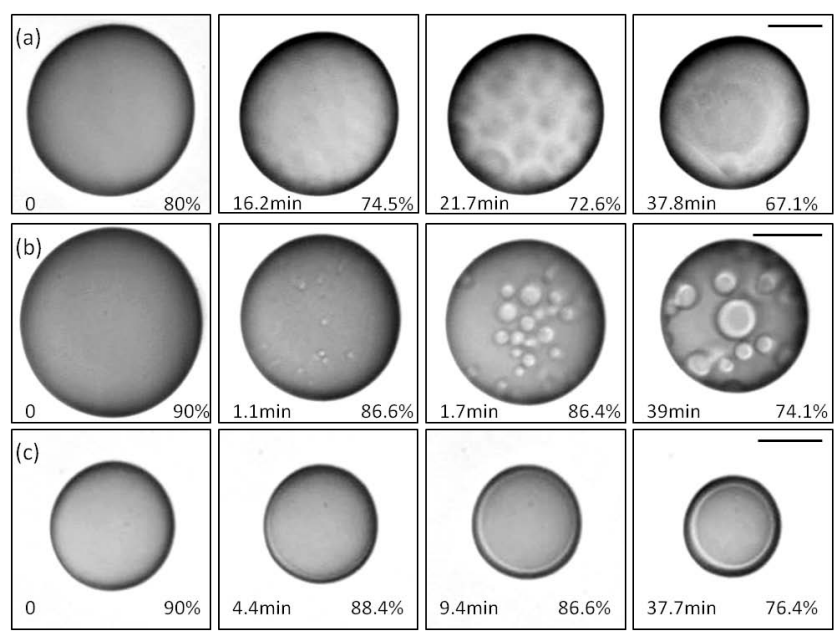

Fig. 7. Series of optical images for different LLPS mechanisms: (a) mechanism unclear (most probably growth and coalescence of organic lenses on the droplet surface) in a $\mathrm{C} 6 / \mathrm{AS} / \mathrm{H}_{2} \mathrm{O}$ particle with $\mathrm{OIR}=1: 4$, (b) nucleation-and-growth with subsequent coalescence in a $\mathrm{C} 7 / \mathrm{AS} / \mathrm{H}_{2} \mathrm{O}$ particle with $\mathrm{OIR}=6: 1$, and (c) growth of second phase from the particle surface in a $\mathrm{C} 7 / \mathrm{AS} / \mathrm{H}_{2} \mathrm{O}$ particle with OIR $=1: 6$. The black bars represent $20 \mu \mathrm{m}$.

an RH change of $20 \%$ ). Here, the organic-rich phase does not seem to spread on the aqueous AS phase but to form droplets or lenses on the surface which might be moved by the $\mathrm{N}_{2} / \mathrm{H}_{2} \mathrm{O}$ flow passing over the particle.

On the other hand, the C7/AS/ $\mathrm{H}_{2} \mathrm{O}$ particles are showing nucleation-and-growth mechanism (example in Fig. 7b), spinodal decomposition, and growth of a second phase at the surface of the particle (example in Fig. $7 \mathrm{c}$ ) at $\mathrm{mf}_{\mathrm{d}}(\mathrm{AS})$ of $<0.30,0.30$ to 0.60 and 0.6 to 1.0 , respectively. These different phase separation mechanisms are indicated as different shadings in Fig. $4 \mathrm{~b}$. 


\subsection{Calculated phase diagrams}

Thermodynamic model calculations for the three systems have been conducted to support the comparison and interpretation of the experimentally determined phase diagrams. While the measurements establish the phase diagrams in the RH vs. dry (water-free) composition space, a thermodynamic calculation reveals the compositions (including water content) of the two phases in liquid-liquid equilibrium (LLE).

On the basis of a mathematically much simpler computation of phase stabilities in case of only three thermodynamically independent components, the limit of stability between metastable and unstable one-phase states, the spinodal curves, were calculated only in case of the ternary systems (see Zuend et al., 2010). However, for reasons of similarity, further discussed below, the computed spinodal curves also support the interpretation of the phase stabilities in case of the $\mathrm{C} 5 / \mathrm{AS} / \mathrm{H}_{2} \mathrm{O}, \mathrm{C} 6 / \mathrm{AS} / \mathrm{H}_{2} \mathrm{O}$, and $\mathrm{C} 7 / \mathrm{AS} / \mathrm{H}_{2} \mathrm{O}$ systems.

Figure 8 shows the computed phase diagrams for the different systems at room temperature. The model predicts a miscibility gap for all systems, the extent of which however differs in composition and $\mathrm{RH}$ range. In agreement with the experimental phase diagrams, the miscibility gap is largest in case of the $\mathrm{C} 7 / \mathrm{AS} / \mathrm{H}_{2} \mathrm{O}$ system and becomes smaller with decreasing size of the dicarboxylic acids and increasing O:C, until it disappears completely. The mass fraction compositions of coexisting phases, as shown in the upper panels of Fig. 8, reveal that water is present in both phases in similar fractions, the difference being largest in case of the $\mathrm{C} 7 / \mathrm{AS} / \mathrm{H}_{2} \mathrm{O}$ system, as seen from the slopes of the tie-lines. However, the difference in water contents is less pronounced when considered in terms of mole fractions since the difference in molar mass of the $\mathrm{C} 5, \mathrm{C} 6$, and $\mathrm{C} 7$ dicarboxylic acids explains a part of the apparent difference between panels (a), (b), and (c). The difference in terms of AS and organic fractions in coexisting phases is much more distinct. This implies that both the dicarboxylic acids and AS (dissociated into $\mathrm{NH}_{4}^{+}$and $\mathrm{SO}_{4}^{2-}$ ions in solution) are quite hydrophilic, but that interactions between the ions and the organics lead to a LLPS at higher AS mass fractions, when, at lower RH, the present fraction of water is not sufficient to moderate those interactions. Since mostly the interactions between non-polar organic molecule segments, here the $\mathrm{CH}_{2}$ and $\mathrm{CH}_{3}$ groups, and ions are causing the phase separation, it is not surprising that the miscibility gap increases with a decrease in the O:C. The model also predicts that all three salt-free systems are miscible with water in all proportions.

While many features of the calculated phase diagrams agree with the droplet experiments at least qualitatively, there are also a number of differences, discussed in the following. Most strikingly, in contrast to the measurements, the model predicts a phase separation region in the $\mathrm{C} 5 / \mathrm{AS} / \mathrm{H}_{2} \mathrm{O}$. In principle, there could also be a phase separation region in the $\mathrm{C} 5 / \mathrm{AS} / \mathrm{H}_{2} \mathrm{O}$ droplets in reality, but only present at $\mathrm{RH}$ below the ERH of the droplets and therefore outside of the experimentally accessible range. However, the model predicts the maximum onset RH of LLPS already at $\sim 60 \%$ $\left(a_{\mathrm{w}}=0.6\right)$, see Fig. 8b. It is therefore obvious, that the predicted onset RH of LLPS is too high, in case of C5/AS/ $\mathrm{H}_{2} \mathrm{O}$ by at least $20 \% \mathrm{RH}$. For an analogous ternary $\mathrm{C} 4 / \mathrm{AS} / \mathrm{H}_{2} \mathrm{O}$ system containing succinic acid, the model still predicts a hypothetical LLPS (not shown), but only below the ERH of AS $(<40 \% \mathrm{RH})$ and only for $\mathrm{mf}_{\mathrm{d}}(\mathrm{AS})$ above 0.6. For a ternary $\mathrm{C} 3 / \mathrm{AS} / \mathrm{H}_{2} \mathrm{O}$ system containing malonic acid, no LLPS is predicted in the entire composition space. Comparisons of predictions and measurements for the $\mathrm{C} 6 / \mathrm{AS} / \mathrm{H}_{2} \mathrm{O}$ and $\mathrm{C} 7 / \mathrm{AS} / \mathrm{H}_{2} \mathrm{O}$ systems, show that the model also predicts higher LLPS onset RH for these systems, with a difference (model - measurement) of $\sim 8 \% \mathrm{RH}$ in case of $\mathrm{C} 6 / \mathrm{AS} / \mathrm{H}_{2} \mathrm{O}$ and $\sim 2 \% \mathrm{RH}$ in case of $\mathrm{C} 7 / \mathrm{AS} / \mathrm{H}_{2} \mathrm{O}$ at $\mathrm{OIR}=1: 1$. These differences are considerably smaller than in the case of the $\mathrm{C} 5 / \mathrm{AS} / \mathrm{H}_{2} \mathrm{O}$ system. Regarding the group-contribution concept used within AIOMFAC to represent organic molecules and their interactions with other species/functional groups, it is not surprising that there are some differences between model predictions and measurements. As described in Zuend et al. (2011), the required AIOMFAC interaction parameters between ions and organic functional groups were determined based on a large, but unevenly distributed amount of experimental data, using a sophisticated parameter optimization procedure to obtain best simultaneous agreement between calculated and measured thermodynamic data. As it turns out, the parameterization database contains mainly water activity data for the optimization of interaction parameters between the $\mathrm{NH}_{4}^{+}$and $\mathrm{SO}_{4}^{2-}$ ions of $\mathrm{AS}$ and the carboxyl group of dicarboxylic acids. Only three solid-liquid equilibria datasets and not a single LLE dataset have been available to better constrain these interactions with potential consequences for the prediction of LLPS. In view of this, the model predictions are in remarkably good agreement with the measured $\mathrm{C} 7 / \mathrm{AS} / \mathrm{H}_{2} \mathrm{O}$ data. The larger deviations between model and measurements in case of the $\mathrm{C} 5 / \mathrm{AS} / \mathrm{H}_{2} \mathrm{O}$ mixtures can also be understood as a result of less constrained AIOMFAC interaction coefficients towards high organic concentrations (and low water mass fractions).

The calculated and measured coexistence curves of the $\mathrm{C} 6 / \mathrm{AS} / \mathrm{H}_{2} \mathrm{O}$ systems agree within $\sim 8 \% \mathrm{RH}$ for $\mathrm{mf}_{\mathrm{d}}(\mathrm{AS})$, from 0.3 to 0.9 . Comparing the coexistence curve of the $\mathrm{C} 6 / \mathrm{AS} / \mathrm{H}_{2} \mathrm{O}$ system at $\mathrm{mf}_{\mathrm{d}}(\mathrm{AS})<0.25$ from Fig. 4a (measurements) with panel (e) of Fig. 8 shows that there is disagreement at those lower salt concentrations. While the model suggests a single mixed phase, the experimental data show that a phase separation is present, however, with rather unusual variations in the LLPS onset RH. For some experiments at compositions $0.19<\mathrm{mf}_{\mathrm{d}}$ (AS) $<0.21$ no LLPS was observed, which would be in agreement with the model results. Moreover, the $\mathrm{mf}_{\mathrm{d}}(\mathrm{AS})$ measured by Raman spectroscopy in the organic-rich phase of $\mathrm{C} 6 / \mathrm{AS} / \mathrm{H}_{2} \mathrm{O}$ phase separated systems agree with a miscibility gap that only extends to $\mathrm{mf}_{\mathrm{d}}$ (AS) of $\sim 0.3$ (Fig. 6a). Furthermore, the measured 

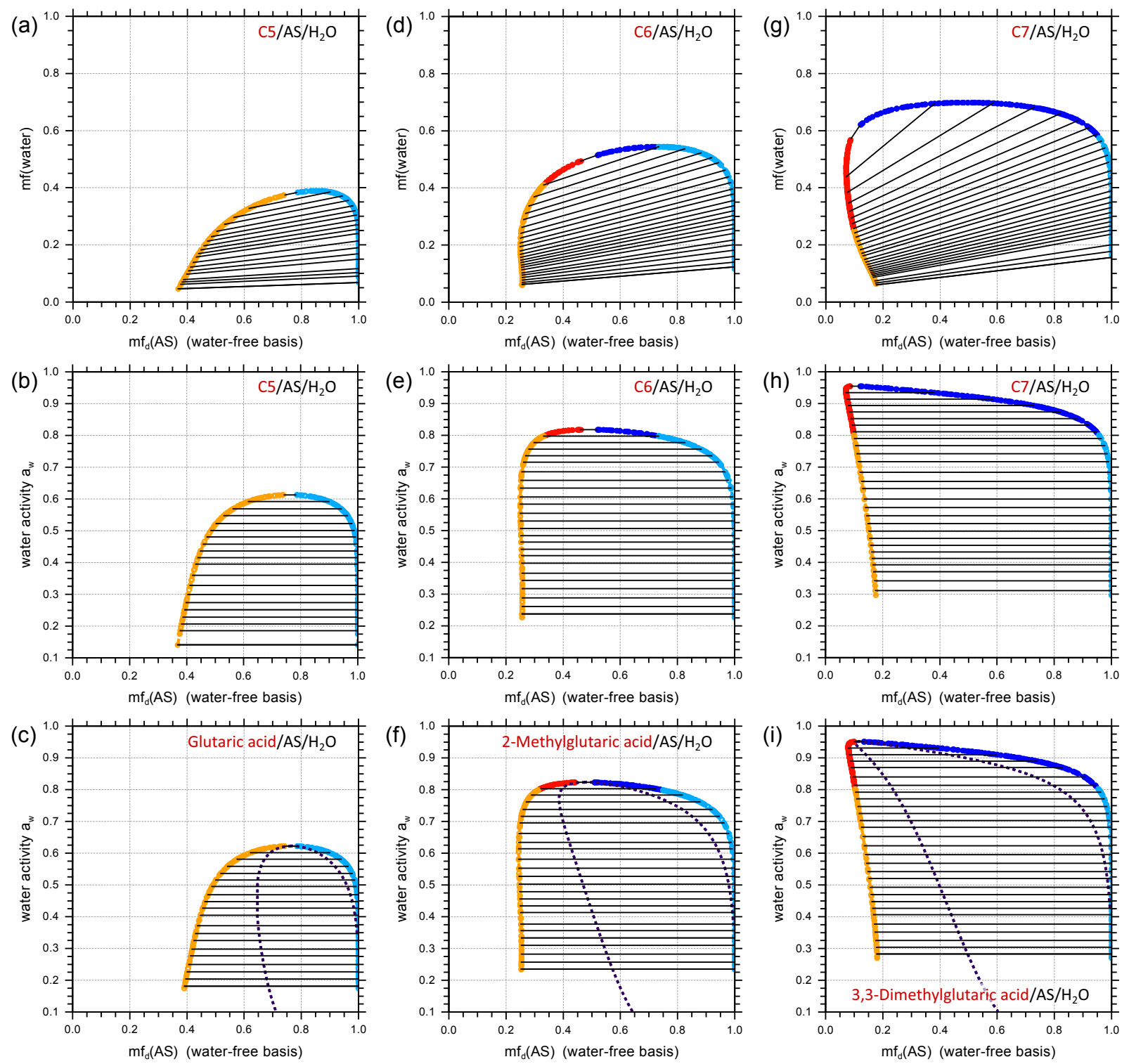

Fig. 8. Predicted phase diagrams of $\mathrm{C} 5 / \mathrm{AS} / \mathrm{H}_{2} \mathrm{O}$ (left), C6/AS/ $\mathrm{H}_{2} \mathrm{O}$ (center), and C7/AS/ $\mathrm{H}_{2} \mathrm{O}$ (right) computed at $298 \mathrm{~K}$ using AIOMFAC. Top panels: liquid-liquid coexistence curve (colored) and tie-lines (black) given as water-free "dry" mass fraction of AS, mf $\mathrm{d}_{\mathrm{d}}$ (AS) vs. mass fraction of water, $\mathrm{mf}$ (water). Each tie-line connects the two coexisting equilibrium phase compositions. Center panels: same as top panels but $\mathrm{mf}$ (water) replaced by water activity $(=\mathrm{RH}$ when liquid and gas phase are in equilibrium). Bottom panels: same as center panels but for ternary systems. Dotted lines: spinodal curves. Coexistence curve colors: red and blue branches indicate aqueous organic-rich phase and aqueous AS-rich phase, respectively. Orange and light blue indicate supersaturation with respect to crystalline AS. The calculated coexistence curves are discontinued at low $a_{\mathrm{W}}$ due to numerical stability issues at very high supersaturation of AS (AS would crystallize before reaching those conditions).

variable AS concentration of the organic-rich phase for OIR $=4: 1$ and higher, suggests that we do not have a regular LLPS in this composition range. The reproducibly high onset and end of LLPS at RH $=85 \%$ for $\mathrm{mf}_{\mathrm{d}}(\mathrm{AS})=0.095$ might be considered as an indication that the minor phase has an almost fixed stoichiometry and might be highly structured. Also, additional ionic species might be important for the formation of this phase because at those lower AS mass fractions and higher water mass fractions, the dicarboxylic acids dissociate to a significant degree, yet concentration dependent and additional ionic species such as bisulfate ions $\left(\mathrm{HSO}_{4}^{-}\right)$form, leading to a different mixture composition (than used in the model calculations). From Fig. 4b, it looks like a similar but less pronounced phase behavior could be present in the $\mathrm{C} 7 / \mathrm{AS} / \mathrm{H}_{2} \mathrm{O}$ droplets at $\mathrm{mf}_{\mathrm{d}}(\mathrm{AS})<0.15$. 

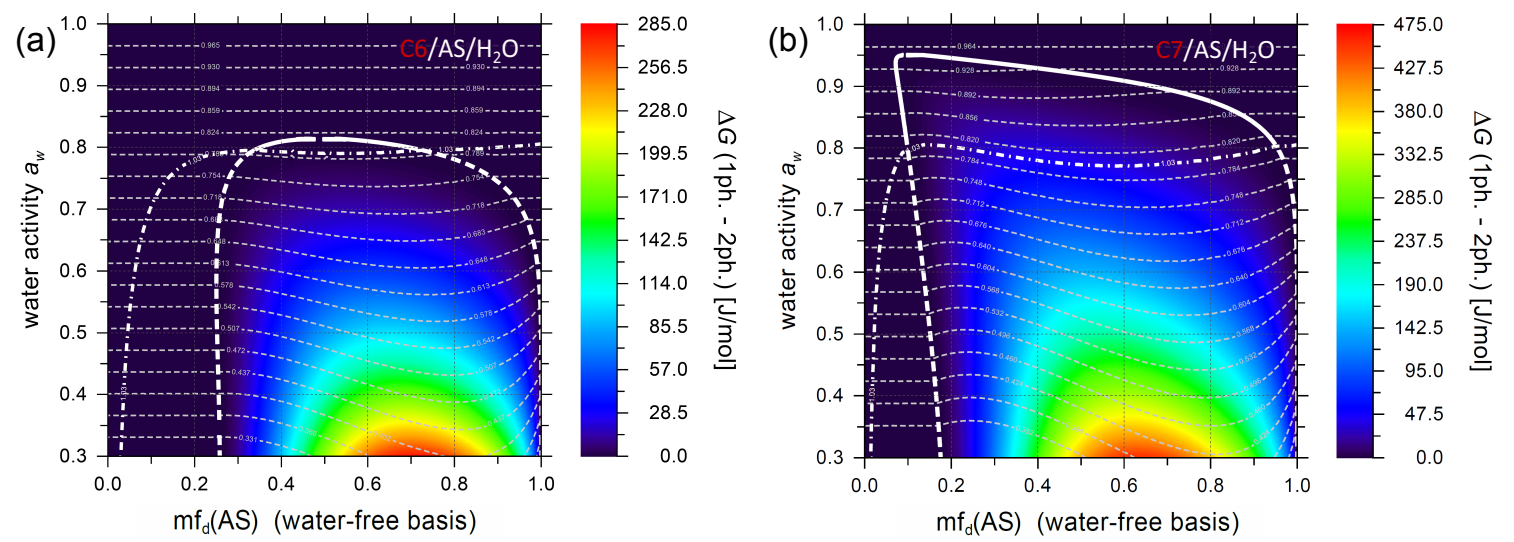

Fig. 9. Calculated Gibbs energy difference $\Delta \mathrm{G}$ (color bar), between a hypothetical one-liquid-phase state (1ph.) and a two-liquid-phases state (2ph.) for (a) the $\mathrm{C} 6 / \mathrm{AS} / \mathrm{H}_{2} \mathrm{O}$ and (b) the $\mathrm{C} 7 / \mathrm{AS} / \mathrm{H}_{2} \mathrm{O}$ system at $298 \mathrm{~K}$. The computed coexistence curves are shown in white (dashed where AS is supersaturated) and correspond to coexistence curves of panels (e) and (h) in Fig. 8. The solubility limit of AS (deliquescence onset) is shown as the white dashed-dotted curve. The light grey dashed lines are isolines of constant equilibrium-state water activity. They represent tie-lines within the LLPS region.

The lower panels (c), (f), and (i) of Fig. 8 show model calculations for ternary mixtures containing glutaric acid, 2methylglutaric acid, and 3,3-dimethylglutaric acid, respectively, corresponding to the 5-component systems of the panels above them. The predicted phase separation regions of the ternary systems are highly similar to those of the corresponding 5-component systems. This result is expected, since the main difference between the 5-component systems and the ternary systems is the mixture of three similar dicarboxylic acids of equal mass, O:C and hydrogen-to-carbon atomic ratios $(\mathrm{H}: \mathrm{C})$, and the same kinds of functional groups, instead of only one dicarboxylic acid. Hence, the applied groupcontribution approach of AIOMFAC can only lead to very small differences among the activity coefficients of structural isomers of dicarboxylic acids in aqueous AS solutions. Based on these phase diagram similarities and the underlying modeling reasons, it is also clear that the calculated spinodal curves of the ternary diagrams apply as well to the 5-component systems. The position and shape of the unstable one-phase region enclosed by the spinodal curve in panels (f) and (i) of Fig. 8, relative to the position of the coexistence curve (binodal), suggests that spinodal decomposition may occur in the $\mathrm{C} 6 / \mathrm{AS} / \mathrm{H}_{2} \mathrm{O}$ system in the composition range of $\sim 0.4<\mathrm{mf}_{\mathrm{d}}$ (AS) $<\sim 0.7$, which is in good agreement with the observed mechanism in the experiments. At higher AS mass fractions, $\operatorname{mf}_{\mathrm{d}}(\mathrm{AS})>\sim 0.7$, a spinodal decomposition could still take place, but the $a_{\mathrm{w}}$-difference between binodal and spinodal curves becomes larger, so that nucleation of a second phase already at a higher RH, before the spinodal curve is reached, becomes more likely. In case of the C7/AS/ $\mathrm{H}_{2} \mathrm{O}$ droplets, the model suggests that spinodal decomposition may occur in the mass fraction range $\sim 0.11<\mathrm{mf}_{\mathrm{d}}(\mathrm{AS})<\sim 0.55$. As compared to the experiments, the predicted range is extended to lower mass fractions of AS; the experiments suggest a lower range limit of $\mathrm{mf}_{\mathrm{d}}(\mathrm{AS})=\sim 0.3$. The measured onset $\mathrm{RH}(89.7 \%)$ for spinodal decomposition in $\mathrm{C} 7 / \mathrm{AS} / \mathrm{H}_{2} \mathrm{O}$ droplets at $\mathrm{OIR}=1: 1$ agrees well with the predicted spinodal curve $(90 \% \mathrm{RH})$ at this composition.

Figure 9 shows the computed Gibbs energy difference between a forced one-liquid-phase state of the mixture and the equilibrium state (two-liquid-phases state in the LLPS region) for the $\mathrm{C} 6 / \mathrm{AS} / \mathrm{H}_{2} \mathrm{O}$ and $\mathrm{C} 7 / \mathrm{AS} / \mathrm{H}_{2} \mathrm{O}$ systems at $298 \mathrm{~K}$ in the RH range from 100 to $30 \%$. Close to the coexistence curve, the Gibbs energy difference $\Delta G$ is rather shallow but increases steeply at lower RH within the phase separation region. This indicates that metastable solutions can exist at water activities slightly below the coexistence curve so that the spinodal limit can be reached in experiments before a nucleation-and-growth event happens. The curvature of the ammonium sulfate solubility limit (the white dashed-dotted curve in Fig. 9) in both systems indicates AS deliquescence RH close to the value in the binary aqueous ammonium sulfate solution for the dry mass fraction range $\sim 0.2<\mathrm{mf}_{\mathrm{d}}(\mathrm{AS}) \leq 1.0$. At higher organic contents, $\mathrm{mf}_{\mathrm{d}}(\mathrm{AS})<\sim 0.2$, the deliquescence $\mathrm{RH}$ drops sharply to lower values due to the reduced amount of AS in the mixture. These DRH predictions agree quite well with the measured AS DRH values shown in Fig. 4.

\subsection{Possible morphologies of droplets on a hydrophobically coated substrate}

The optical microscope gives only the top view of the droplets on the substrate. It is therefore not possible to directly observe whether inclusions of the minor phase have contact to the droplet/air or the droplet/substrate interface or whether they are floating within the droplet volume. 
(a)

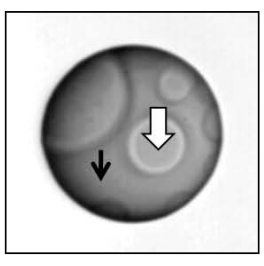

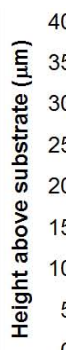

(b)
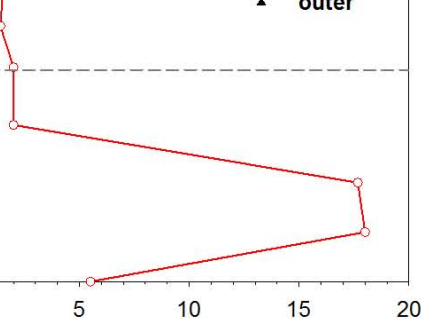

(c)

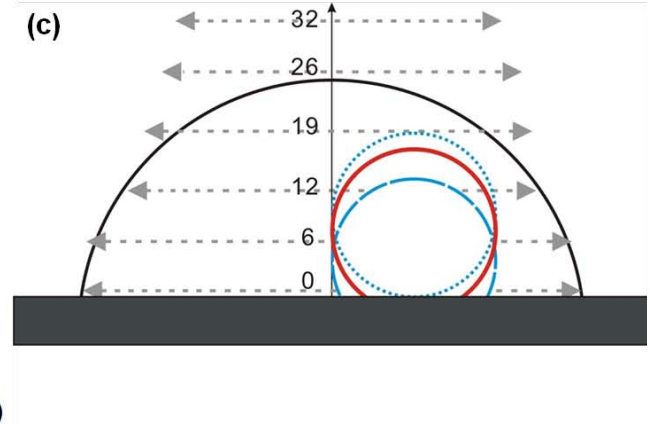

Fig. 10. Raman scan through a $\mathrm{C} 6 / \mathrm{AS} / \mathrm{H}_{2} \mathrm{O}$ droplet with $\mathrm{OIR}=1: 1$ on the hydrophobic coated substrate at $65 \% \mathrm{RH}$. Panel (a): optical image of the droplet $(58.9 \mu \mathrm{m}$ in diameter). The white arrow indicates the position of the Raman scan through the AS inclusion $(\sim 19.0 \mu \mathrm{m}$ in diameter). Panel (b): ratios of AS $\left(979 \mathrm{~cm}^{-1}\right)$ and C6 $\left(2931 \mathrm{~cm}^{-1}\right)$ Raman peak intensities. Red circles: vertical scan through the droplet at the position indicated by the white arrow in (a). Black triangle: reference point representing the AS/C6 Raman ratio of the outer phase measured at the position indicated by the black arrow in the (a). The gray dashed line sets the maximum height of the droplet $(25.4 \mu \mathrm{m})$ as reconstructed in panel (c). Panel (c): reconstructed side view of the droplet (black curved line) on the substrate and the inclusion (red) indicated by the white arrow in panel (a). In blue are shown inclusions with upper and lower limits of the estimated contact angle range from 105 to $140^{\circ}$. The horizontal gray arrows correspond to the particle diameter $(\mu \mathrm{m})$ measured from the microscopic images at each scanning level of the droplet (red open circles in panel b).

To resolve this issue, we performed confocal Raman scans through the droplets by changing the laser focus from the bottom to the top of the droplets with step sizes of 6-7 $\mu \mathrm{m}$. Figure 10 shows an example of such a vertical scan. Panel (a) gives the optical image of the droplet. The scan was performed through an inclusion with a diameter of $\sim 19 \mu \mathrm{m}$ (marked by a white arrow). For comparison, a Raman spectrum of the outer phase (marked by a black arrow) was also collected. Evaluation of the Raman spectra relied on the ratio of the peak height of the main peaks of AS $\left(979 \mathrm{~cm}^{-1}\right)$ and C6 $\left(2931 \mathrm{~cm}^{-1}\right)$. This AS/C6 peak ratio is shown in Fig. $10 \mathrm{~b}$ as a function of laser focus within the droplet. We determined the bottom of the droplet (droplet height $=0 \mu \mathrm{m}$ ) optically as the point where the rim of the droplet appeared sharp and the diameter of the droplet was largest. Moving the focus upwards, the observed diameter decreased (gray arrows in c) and the droplet edge became increasingly blurred making the diameter measurement inaccurate. To determine the top of the droplet, we in addition reconstructed the droplet shape assuming a spherical cap with a contact angle of $81.6 \pm 2^{\circ}$ (determined for $2 \mu \mathrm{l} 6 / \mathrm{AS} / \mathrm{H}_{2} \mathrm{O}$ droplets with OIR $=1: 1(\approx 40 \mathrm{wt} \%(\mathrm{C} 6+\mathrm{AS}))$ deposited on the hydrophobically coated substrate (see panel c) leading to a droplet height of $25.4 \mu \mathrm{m}$ for the investigated droplet with diameter of $58.9 \mu \mathrm{m}$. This droplet height is given as dashed gray line in (b). The highest AS/C6 Raman peak ratios were measured at droplet heights of 6 and $12 \mu \mathrm{m}$. Above $20 \mu \mathrm{m}$ the AS/C6 peak ratio remained constant at a value slightly above the one of the outer phase (given as a black triangle in b) while the absolute Raman intensities decreased because the laser focus was moving out of the droplet. This clearly shows that the inclusion was at the bottom of the droplet, probably with a high contact angle to the substrate $\left(>90^{\circ}\right)$ or form- ing almost a sphere. We performed similar experiments for two other droplets with smaller inclusions $(\sim 10 \mu \mathrm{m}$ diameter), which clearly showed that these inclusions were also at the bottom of the droplet. This morphology is also supported by the calculation of the settling velocity of aqueous AS inclusions in the organic-rich phase: settling of 10 and $20 \mu \mathrm{m}$ diameter AS-rich phase inclusions should occur at a rate of $0.5-3.3$ and $2-13 \mu \mathrm{m} \mathrm{min}^{-1}$, respectively. We therefore expect that the AS-rich inclusions settle to the bottom of the droplet driven by gravity within the timescale of the experiment (see Appendix A for details of the calculation).

In all investigated $\mathrm{C} 6 / \mathrm{AS} / \mathrm{H}_{2} \mathrm{O}$ droplets with $\mathrm{OIR}=1: 1$, the main AS inclusion moved from the middle to the edge of the droplet between $\sim 70-66 \% \mathrm{RH}$ and remained in this partially engulfed configuration down to ERH. A similar behavior was observed for $\mathrm{C} 6 / \mathrm{AS} / \mathrm{H}_{2} \mathrm{O}$ droplets between $\sim 63$ $50 \% \mathrm{RH}$ with $\mathrm{OIR}=1: 2$. Partial engulfed configurations were also observed for $\mathrm{C} 7 / \mathrm{AS} / \mathrm{H}_{2} \mathrm{O}$ droplets $\sim 88 \% \mathrm{RH}$ with $\mathrm{OIR}=2: 1$.

The morphology of droplets with sizes of several tens of micrometers is influenced by surface and interfacial forces and by gravity. The spreading coefficient (Torza and Mason, 1970; Kwamena et al., 2010; Reid et al., 2011) can be used to predict the equilibrium morphology of two immiscible phases when in contact with each other. The spreading coefficient $\left(S_{i}\right)$ of a liquid component $(i)$ spreading over another component $(j)$ can be determined when the surface $\left(\sigma_{j k}, \sigma_{i k}\right)$ and interfacial tensions $\left(\sigma_{i j}\right)$ are known:

$S_{i}=\sigma_{j k}-\left(\sigma_{i j}+\sigma_{i k}\right)$.

For a partial engulfed configuration, the spreading coefficient of the organic-rich phase on the aqueous phase needs to be smaller than zero, which implies an interfacial tension 


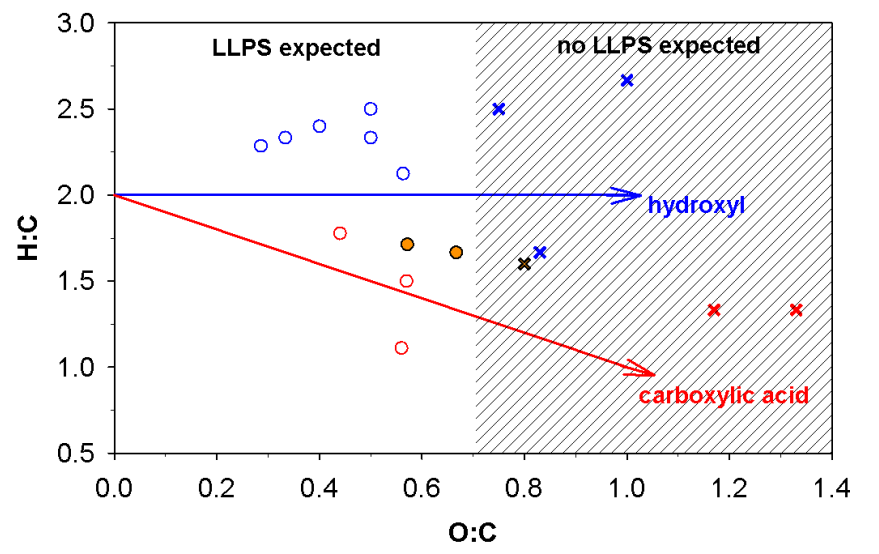

- LLPS, hydroxyl/AS/ $/ \mathrm{H}_{2} \mathrm{O}, \mathrm{PEG}-400 / \mathrm{AS} / \mathrm{H}_{2} \mathrm{O}$

no LLPS, hydroxyl/AS/ $/ \mathrm{H}_{2} \mathrm{O}$

LLPS, aromatic or aliphatic carboxylic acid/AS/ $/ \mathrm{H}_{2} \mathrm{O}$

no LLPS, aromatic or aliphatic carboxylic acid/AS/ $/ \mathrm{H}_{2} \mathrm{O}$

LLPS, dicarboxylic acids $/ A S / \mathrm{H}_{2} \mathrm{O}$ (This study)

no LLPS, dicarboxylic acids/AS/ $\mathrm{H}_{2} \mathrm{O}$ (This study)

Fig. 11. Van Krevelen diagram showing organic/AS/ $\mathrm{H}_{2} \mathrm{O}$ systems with LLPS (circles) and without LLPS (crosses) from previous work (Marcolli and Krieger, 2006; Zuend et al., 2008; Ciobanu et al., 2009; Bertram et al., 2011, see Table 2 for the datasets) and this study (orange symbols). The blue and red arrows correspond to the addition of hydroxyl and carboxylic acid (or hydroxyl + ketone/aldehyde) functional groups to an alkane backbone, respectively, as discussed in Heald et al. (2010).

between the two liquid phases of $\sigma_{\mathrm{org}} / \mathrm{AS}>\sigma_{\mathrm{AS}}-\sigma_{\mathrm{org}}$. Assuming an upper limit for the surface tension of the C6-rich phase of $\sigma_{\mathrm{org}}=52 \mathrm{mN} \mathrm{m}^{-1}$ and a lower limit for the AS-rich phase of $\sigma_{\mathrm{AS}}=67 \mathrm{mN} \mathrm{m}^{-1}$ (see Appendix B for estimates of surface and interfacial tensions), an interfacial tension of at least $15 \mathrm{mN} \mathrm{m}^{-1}$ is required for a partial engulfed configuration, which is in the typical range of interfacial tensions of aqueous/organic two-liquid-phases systems. It can be assumed that the interfacial tension increases with decreasing RH because water as mediating component between the phases becomes more and more scarce. Between 70$66 \% \mathrm{RH}$ the interfacial tension seems to reach a critical value where the spreading coefficient of the C6-rich phase changes sign from a positive to a negative value making a partially engulfed configuration energetically more favorable.

Using Young's equation, the contact angle of the aqueous AS inclusion with the substrate can be estimated (see Appendix B), leading to values in the range of $105-140^{\circ}$. Droplets with these lower and upper values are sketched in blue in Fig. 10c, the best estimation of the droplet's morphology is given in red.

\subsection{Atmospheric implications}

Recently, O:C has been stressed as crucial parameter to describe hygroscopicity (Jimenez et al., 2009), oxidation
(Heald et al., 2010; Kroll et al., 2011), volatility and mixing thermodynamics of organic aerosol (Donahue et al., 2011). $\mathrm{O}: \mathrm{C}$ and $\mathrm{H}: \mathrm{C}$ of ambient and laboratory aerosol particles can be derived from analysis of high resolution mass spectral data (Aiken et al., 2007, 2008). Heald et al. (2010) established that atmospheric organic aerosols, obtained from various field measurements and laboratory studies, cluster along a narrow line with a slope of -1 in Van Krevelen space (H:C vs. O:C). O:C can also be an indicator of phase separation of mixed particles. Figure 11 gives the position of the organic components of hydroxyl and PEG-400/AS/ $\mathrm{H}_{2} \mathrm{O}$ (blue) and aromatic or aliphatic carboxylic acid/AS/ $\mathrm{H}_{2} \mathrm{O}$ systems (red) from literature (see Table 2) in the Van Krevelen diagram. The $\mathrm{C} 5 / \mathrm{AS} / \mathrm{H}_{2} \mathrm{O}, \mathrm{C} 6 / \mathrm{AS} / \mathrm{H}_{2} \mathrm{O}$ and $\mathrm{C} 7 / \mathrm{AS} / \mathrm{H}_{2} \mathrm{O}$ systems from this study are also included (orange symbols). It can be seen that systems with O:C $<0.7$ show LLPS (circles) while systems with $\mathrm{O}: \mathrm{C}>0.7$ do not (crosses). This is in perfect agreement with Bertram et al. (2011) who reported in a recent study that $\mathrm{O}: \mathrm{C}$ is a critical factor for LLPS of aerosol particles and showed that there is no phase separation for $\mathrm{O}: \mathrm{C}>0.7$ for various single organic compounds in the presence of AS. Therefore, we expect that in the troposphere LLPS occurs in mixtures of AS and organic components with an $\mathrm{O}: \mathrm{C}<0.7$. Analysis of ambient data indicates $\mathrm{O}: \mathrm{C}$ up to 0.6 for semivolatile oxygenated organic aerosols (SV-OOA) and from $0.5-1.1$ for low volatility OOA (LV-OOA) (Ng et al., 2011). All of the SV-OOA and a part of the LV-OOA, therefore, fall into the O:C range for which we expect LLPS. The degree of oxidation that chamber organic aerosol reach strongly depend on the volatile organic precursor molecules: secondary organic aerosol (SOA) formed by oxidation of $\alpha$-pinene, isoprene, $m$-xylene and toluene mostly exhibit $\mathrm{O}: \mathrm{C}<0.7$ while e.g. acrolein and glyoxal SOA cover O:C $>0.7$ (Chhabra et al., 2011). In addition, LLPS might promote the formation of particles with highly viscous and glassy coatings because the more viscous organic components are spatially separated from the less viscous inorganic salt solution. In this study, partially engulfed configuration was observed in the $\mathrm{C} 6 / \mathrm{AS} / \mathrm{H}_{2} \mathrm{O}$ system for $\mathrm{OIR}=1: 1$ and 1:2 while both partial $(\mathrm{OIR}=2: 1)$ and complete engulfed (OIR $=1: 1)$ configurations occurred in the $\mathrm{C} 7 / \mathrm{AS} / \mathrm{H}_{2} \mathrm{O}$ system. No size dependence of the morphology was observed for particles within the investigated size ranges. Due to the Kelvin effect, more complex morphologies are thermodynamically not favored in accumulation mode particles. Based on this and other recent studies (Ciobanu et al., 2009; Kwamena et al., 2010; Bertram et al., 2011; Reid et al., 2011), core-shell and partially engulfed configurations seem to occur. A core-shell configuration will have more drastic consequences for heterogeneous chemistry and hygroscopicity than a partially engulfed configuration because the aqueous inorganic-rich phase will be totally enclosed by a probably highly viscous organic coating with low diffusivity for reactants and water. E.g., atmospheric chemistry related to the $\mathrm{N}_{2} \mathrm{O}_{5}$ heterogeneous hydrolysis onto 
Table 2. List of "no LLPS" and "LLPS" exhibiting mixtures consisting of aqueous AS with organic components containing hydroxyl $(\mathrm{OH})$, carboxyl $(\mathrm{COOH})$, ether $\left(\mathrm{CH}_{\mathrm{n}} \mathrm{O}\right)$, ester $(\mathrm{CCOO})$, and aromatic $\left(\mathrm{ACH}_{\mathrm{n}}\right)$ functional groups. Range of experimental conditions: $30 \%<\mathrm{RH}<100 \%$ and $\mathrm{mf}_{\mathrm{d}}(\mathrm{AS})>0.1$. Data from the literature and this work.

\begin{tabular}{|c|c|c|c|c|c|}
\hline Compounds & Formula & $\begin{array}{l}\text { Functional } \\
\text { Groups }\end{array}$ & $\mathrm{O}: \mathrm{C}$ & $\mathrm{H}: \mathrm{C}$ & References \\
\hline \multicolumn{6}{|l|}{ no LLPS } \\
\hline glycerol & $\mathrm{C}_{3} \mathrm{H}_{8} \mathrm{O}_{3}$ & $\mathrm{OH}$ & 1.00 & 2.67 & $\begin{array}{l}\text { Marcolli and Krieger (2006) } \\
\text { Bertram et al. (2011) }\end{array}$ \\
\hline 1,2,4-butanetriol & $\mathrm{C}_{4} \mathrm{H}_{10} \mathrm{O}_{3}$ & $\mathrm{OH}$ & 0.75 & 2.50 & Zuend et al. (2008) \\
\hline $\begin{array}{l}\text { 6,8-dioxabicyclo[3.2.1] octane- } \\
\text { 2,3,4-triol }\end{array}$ & $\mathrm{C}_{6} \mathrm{H}_{10} \mathrm{O}_{5}$ & $\mathrm{CH}_{\mathrm{n}} \mathrm{O}, \mathrm{OH}$ & 0.83 & 1.67 & Bertram et al. (2011) \\
\hline pentanedioic acid & $\mathrm{C}_{5} \mathrm{H}_{8} \mathrm{O}_{4}$ & $\mathrm{COOH}$ & 0.80 & 1.60 & Bertram et al. (2011) \\
\hline citric acid & $\mathrm{C}_{6} \mathrm{H}_{8} \mathrm{O}_{7}$ & $\mathrm{COOH}, \mathrm{OH}$ & 1.17 & 1.33 & Bertram et al. (2011) \\
\hline propanedioic acid & $\mathrm{C}_{3} \mathrm{H}_{4} \mathrm{O}_{4}$ & $\mathrm{COOH}$ & 1.33 & 1.33 & Bertram et al. (2011) \\
\hline $\begin{array}{l}\text { C5: glutaric acid } \\
\quad+\text { dimethylmalonic acid } \\
\text { + methylsuccinic acid }\end{array}$ & $\mathrm{C}_{5} \mathrm{H}_{8} \mathrm{O}_{4}$ & $\mathrm{COOH}$ & 0.80 & 1.60 & This work \\
\hline \multicolumn{6}{|l|}{ LLPS } \\
\hline 1,2-hexanediol & $\mathrm{C}_{6} \mathrm{H}_{14} \mathrm{O}_{2}$ & $\mathrm{OH}$ & 0.33 & 2.33 & Marcolli and Krieger (2006) \\
\hline 1,4-butanediol & $\mathrm{C}_{4} \mathrm{H}_{10} \mathrm{O}_{2}$ & $\mathrm{OH}$ & 0.50 & 2.50 & Marcolli and Krieger (2006) \\
\hline 1,2,6-hexane-triol & $\mathrm{C}_{6} \mathrm{H}_{14} \mathrm{O}_{3}$ & $\mathrm{OH}$ & 0.50 & 2.33 & Bertram et al. (2011) \\
\hline 2,4-pentanediol & $\mathrm{C}_{5} \mathrm{H}_{12} \mathrm{O}_{2}$ & $\mathrm{OH}$ & 0.40 & 2.40 & Zuend et al. (2008) \\
\hline 2,5-hexanediol & $\mathrm{C}_{6} \mathrm{H}_{14} \mathrm{O}_{2}$ & $\mathrm{OH}$ & 0.33 & 2.33 & Zuend et al. (2008) \\
\hline 1,7-heptanediol & $\mathrm{C}_{7} \mathrm{H}_{16} \mathrm{O}_{2}$ & $\mathrm{OH}$ & 0.29 & 2.29 & Zuend et al. (2008) \\
\hline monomethyloctane-1,8-dioate & $\mathrm{C}_{9} \mathrm{H}_{16} \mathrm{O}_{4}$ & $\mathrm{COOH}, \mathrm{CCOO}$ & 0.44 & 1.78 & Bertram et al. (2011) \\
\hline $\begin{array}{l}\text { 4-dihydroxy-3- } \\
\text { methoxybenzeneacetic acid }\end{array}$ & $\mathrm{C}_{9} \mathrm{H}_{10} \mathrm{O}_{5}$ & $\begin{array}{l}\mathrm{COOH}, \mathrm{OH} \\
\mathrm{CH}_{\mathrm{n}} \mathrm{O}, \mathrm{ACH}_{\mathrm{n}}\end{array}$ & 0.56 & 1.11 & Bertram et al. (2011) \\
\hline 2,5-dihydroxybenzoic acid & $\mathrm{C}_{7} \mathrm{H}_{6} \mathrm{O}_{4}$ & $\begin{array}{l}\mathrm{COOH}, \mathrm{OH} \\
\mathrm{ACH}_{\mathrm{n}}\end{array}$ & 0.57 & 1.50 & Bertram et al. (2011) \\
\hline 2,2-dimethylbutanedioic acid & $\mathrm{C}_{6} \mathrm{H}_{10} \mathrm{O}_{4}$ & $\mathrm{COOH}, \mathrm{OH}$ & 0.67 & 1.67 & Bertram et al. (2011) \\
\hline PEG-400 & $\begin{array}{l}\mathrm{C}_{2 \mathrm{n}} \mathrm{H}_{4 \mathrm{n}+2} \mathrm{O}_{\mathrm{n}+1} \\
(\mathrm{n}=8-9)\end{array}$ & $\mathrm{OH}, \mathrm{CH}_{\mathrm{n}} \mathrm{O}$ & $\sim 0.56$ & $\sim 2.12$ & Ciobanu et al. (2009) \\
\hline $\begin{aligned} \text { C6: } & \text { 2-methylglutaric acid } \\
& +3 \text {-methylglutaric acid } \\
& +2,2 \text {-dimethylsuccinic acid }\end{aligned}$ & $\mathrm{C}_{6} \mathrm{H}_{10} \mathrm{O}_{4}$ & $\mathrm{COOH}$ & 0.67 & 1.67 & This work \\
\hline $\begin{aligned} \text { C7: } & \text { 3-methyladipic acid } \\
& +3,3 \text {-dimethylglutaric acid } \\
& + \text { diethylmalonic acid }\end{aligned}$ & $\mathrm{C}_{7} \mathrm{H}_{12} \mathrm{O}_{4}$ & $\mathrm{COOH}$ & 0.57 & 1.71 & This work \\
\hline
\end{tabular}

organic coated aerosol particles is strongly influenced by particle morphology (Thornton and Abbatt, 2005; Anttila et al., 2006; Cosman and Bertram, 2008; Cosman et al., 2008). Significant reduction in reactive uptake coefficient with a factor of 2-42 has been observed with dependence on organic components on aqueous sulfuric acid solutions. Assuming that the aqueous AS phase is surrounded by the organic-rich phase, the $\mathrm{N}_{2} \mathrm{O}_{5}$ hydrolysis may be suppressed effectively.

\section{Conclusions}

We investigated phase transitions of micrometer-sized particles consisting of multicomponent mixtures of AS and C5,
C6, and C7 dicarboxylic acids having O:C of $0.80,0.67$, and 0.57 , respectively, during humidity cycles. We used optical microscopy to follow phase changes and Raman spectroscopy to infer chemical composition. Micrometersized particles of C5/AS/ $\mathrm{H}_{2} \mathrm{O}, \mathrm{C} 6 / \mathrm{AS} / \mathrm{H}_{2} \mathrm{O}$, and $\mathrm{C} 7 / \mathrm{AS} / \mathrm{H}_{2} \mathrm{O}$ showed significantly different phase transition behavior during $\mathrm{RH}$ cycles. While the $\mathrm{C} 5 / \mathrm{AS} / \mathrm{H}_{2} \mathrm{O}$ particles showed no LLPS with $\mathrm{OIR}=2: 1,1: 1$, and $1: 4$, the $\mathrm{C} 6 / \mathrm{AS} / \mathrm{H}_{2} \mathrm{O}$ and $\mathrm{C} 7 / \mathrm{AS} / \mathrm{H}_{2} \mathrm{O}$ particles exhibit LLPS upon drying at $\mathrm{RH}$ between 50 and $85 \%$ and at $\sim 90 \%$, respectively, depending on the OIR. Phase equilibria calculations using AIOMFAC are for the most part in good agreement with the experimentally determined phase diagrams. From the investigated systems and literature data, we suggest that LLPS commonly occurs 
in atmospheric aerosol particles with $\mathrm{O}: \mathrm{C}<0.7$. This is in excellent agreement with a very recent study by Bertram et al. (2011). Further investigations have to show how sensitive this limit is to the specific chemical composition of the organic and inorganic aerosol fractions, temperature, and the complexity of the organic fraction in aerosols.

Core-shell structure and partially engulfed configurations were observed in the particles on a hydrophobically coated substrate and therefore such morphologies might very likely be present in the troposphere. A core-shell configuration will have consequences for heterogeneous chemistry and hygroscopicity because the aqueous inorganic-rich phase will be totally enclosed by a probably highly viscous organic coating with low diffusivity for reactants and water. Definitive conclusions whether a core-shell or a partially engulfed morphology is prevalent in airborne particles is not possible from the present study because all experiments have been performed on a hydrophobically coated substrate, which might influence surface forces and the preferred morphology. Supplementary experiments should therefore be carried out on levitated particles in an electrodynamic balance or optical tweezers. Since also levitated particles are subject to additional forces that are not present in atmospheric aerosols, these measurements should be complemented by calculations of the preferred morphology using accurate surface and interfacial tension data of the investigated mixtures.

\section{Appendix A}

\section{Settling velocity}

The settling velocity $(v)$ of an AS-rich inclusion within a C6rich fluid is given by Stokes' law:

$v=\frac{2\left(\rho_{\mathrm{i}}-\rho_{\mathrm{f}}\right) g r^{2}}{9 \mu}$

where $\rho_{\mathrm{i}}$ and $\rho_{\mathrm{f}}$ are the densities of the inclusion and the fluid, respectively, $g$ the gravitational acceleration, $r$ the radius of the inclusion and $\mu$ the viscosity of the fluid. At $a_{\mathrm{w}}=0.7$, AS solution density is calculated as $1.30 \mathrm{~g} \mathrm{~cm}^{-3}$ at $20^{\circ} \mathrm{C}$ using the parameterization by Tang and Munkelwitz (1994). We estimate the density of the C6-rich phase at $a_{\mathrm{w}}=0.7$ and $20^{\circ} \mathrm{C}$ as $1.20-1.23 \mathrm{~g} \mathrm{~cm}^{-3}$ by extrapolating the densities of solutions of the structurally similar glutaric acid (Ben-Hamo et al., 2007) to estimated solute mass fractions of $0.75-0.80$ at $a_{\mathrm{w}}=0.7$. Hence, we expect the aqueous AS phase to be of higher density than the organic-rich one.

The viscosity of aqueous adipic acid, the straight-chain C6 dicarboxylic acid, has only been measured for dilute solutions (Chmielewska and Bald, 2008). In the range where data is available, densities of aqueous solutions of adipic, glutaric, and citric acid show all similar concentration dependences (Laguerie et al., 1976; Chmielewska and Bald, 2008). To estimate the viscosity of the C6-rich phase, we therefore extrapolate the citric acid values to concentrations corresponding to solute mass fractions of $0.75-0.80$, yielding viscosities of $100-500 \mathrm{mPa}$. Applying these values, settling of 10 and $20 \mu \mathrm{m}$ diameter AS-rich phase inclusions should occur at a rate of $0.5-3.3$ and $2-13 \mu \mathrm{m} \mathrm{min}^{-1}$, respectively. We therefore expect that the AS-rich inclusions settle to the bottom of the droplet driven by gravity within the timescale of the experiment, which is in accordance with the observed morphology of the Raman scans.

\section{Appendix B}

\section{Estimation of surface and interfacial tensions}

Surface tensions of aqueous solutions of the straight chain dicarboxylic acids have been measured by several groups (e.g. Shulman et al., 1996; Varga et al., 2007). A decrease of surface tension is observed with increasing solute concentration. For $1-2 \mathrm{wt} \%$ aqueous adipic acid (C6) solutions surface tensions of $\sim 68 \mathrm{mN} \mathrm{m}^{-1}$ (pure water case: $\sim 72 \mathrm{mN} \mathrm{m}^{-1}$ ) and for $30-40 \%$ aqueous glutaric acid (C5) solutions a reduction of 10-20\% has been reported (Shulman et al., 1996; Varga et al., 2007; Booth et al., 2009). Topping et al. (2007) give values for adipic acid surface tension in the supercooled liquid state of $45.5 \mathrm{mN} \mathrm{m}^{-1}$ and $52.4 \mathrm{mN} \mathrm{m}^{-1}$ depending on estimation method. The organic-rich phase in $\mathrm{C} 6 / \mathrm{AS} / \mathrm{H}_{2} \mathrm{O}$ droplets is highly concentrated and we expect it to exhibit similar surface tensions as the supercooled liquid state of adipic acid, i.e. $45-52 \mathrm{mN} \mathrm{m}^{-1}$. Surface tension in AS solutions is increased by $20 \%$ at AS saturation $\left(a_{\mathrm{w}}=0.8\right.$ at $\left.25^{\circ} \mathrm{C}\right)$ compared with pure water and is expected to increase even more in the supersaturated regime (Lewis, 2006). However, in the presence of small amounts of adipic acid $(\sim 0.5 \mathrm{wt} \%)$, this trend is reversed and surface tension decreases with increasing AS concentration (Booth et al., 2009). A solution containing 0.0007 mole fraction adipic acid and 0.009 mole fraction AS exhibited a surface tension of $67.1 \mathrm{mN} \mathrm{m}^{-1}$. This value might quite well represent the surface tension of the AS-rich phase in the $\mathrm{C} 6 / \mathrm{AS} / \mathrm{H}_{2} \mathrm{O}$ droplets.

Interfacial tensions of binary aqueous/organic two-phase systems typically vary between $6-52 \mathrm{mN} \mathrm{m}^{-1}$ (Backes et al., 1990). On the other hand, aqueous two-phase systems consisting of immiscible aqueous phases of incompatible polymers, surfactants or salts exhibit very low interfacial tensions $\left(<1 \mathrm{mN} \mathrm{m}^{-1}\right)$ (Giraldo-Zuniga et al., 2006; Nan et al., 2006; Spyropoulos et al., 2008).

Young's equation relates the interfacial forces $(\sigma)$ to the contact angle $(\theta)$ that a droplet (d) in a fluid (f) makes with the surface (s):

$\sigma_{\mathrm{s} / \mathrm{d}}+\sigma_{\mathrm{d} / \mathrm{f}} \cos \theta=\sigma_{\mathrm{s} / \mathrm{f}}$. 
The fluid (f) is usually, but not necessarily, the vapor phase. Using this relation, the contact angle of the minor-phase inclusions on the substrate can be roughly estimated. In a first step, the interfacial tensions between the substrate and the C6-rich phase $\sigma_{\mathrm{org} / \mathrm{s}}$ and the substrate and the AS-rich phase $\sigma_{\mathrm{AS} / \mathrm{s}}$ can be estimated using the following values for the surface tensions of the substrate $\sigma_{\mathrm{s}}=25.3 \mathrm{mN} \mathrm{m}^{-1}$ (Frank and Belfort, 2001), the C6-rich phase $\sigma_{\text {org }}=45-52 \mathrm{mN} \mathrm{m}^{-1}$, and the AS-rich phase $\sigma_{\mathrm{AS}}=67.1 \mathrm{mN} \mathrm{m}^{-1}$, and contact angles for saturated C6 and $40 \mathrm{wt} \%$ AS droplets of $76.7 \pm 2.8^{\circ}$ and $94.0 \pm 1.1^{\circ}$, respectively. This yields $\sigma_{\mathrm{org} / \mathrm{s}}=17.7-18.7^{\circ}$ and $\sigma_{\mathrm{AS} / \mathrm{s}}=25.3^{\circ}$. Using these numbers and lower and upper limits of interfacial tension $\sigma_{\mathrm{org} / \mathrm{AS}}$ of 15 and $44 \mathrm{mN} \mathrm{m}^{-1}$, respectively, yields contact angles of $105-140^{\circ}$.

Acknowledgements. This work was supported by the Swiss National Foundation Project No. 200020-125151 and the Competence Center Environment and Sustainability of the ETH Domain (CCES) project IMBALANCE. We thank Uwe Weers and Edwin Hausammann for technical support. M. Song gives special thanks to C. Chou for the scientific discussion.

Edited by: N. M. Donahue

\section{References}

Aiken, A. C., DeCarlo, P. F., and Jimenez, J. L.: Elemental analysis of organic species with electron ionization highresolution mass spectrometry, Anal. Chem., 79, 8350-8358, doi:8310.1021/ac071150w, 2007.

Anttila, T., Kiendler-Scharr, A., Tillmann, R., and Mentel, T. F.: On the reactive uptake of gaseous compounds by organic-coated aqueous aerosols: Theoretical analysis and application to the heterogeneous hydrolysis of $\mathrm{N}_{2} \mathrm{O}_{5}$, J. Phys. Chem. A., 110, 1043510443, doi:10.1021/Jp062403c, 2006

Anttila, T., Kiendler-Scharr, A., Mentel, T. F., and Tillmann, R.: Size dependent partitioning of organic material: evidence for the formation of organic coatings on aqueous aerosols, J. Phys. Chem. A., 57, 215-237, doi:10.1007/s10874-007-9067-9, 2007.

Aiken, A. C., DeCarlo, P. F., Kroll, J. H., Worsnop, D. R., Huffman, J. A., Docherty, K. S., Ulbrich, I. M., Mohr, C., Kimmel, J. R., Sueper, D., Sun, Y., Zhang, Q., Trimborn, A., Northway, M., Ziemann, P. J., Canagaratna, M. R., Onasch, T. B., Alfarra, M. R., Prevot, A. S. H., Dommen, J., Duplissy, J., Metzger, A., Baltensperger, U., and Jimenez, J. L.: O/C and OM/OC ratios of primary, secondary, and ambient organic aerosols with high-resolution time-of-flight aerosol mass spectrometry, Environ. Sci. Technol., 42, 4478-4485, 2008.

Backes, H. M., Jing, J. M., Bender, E., and Maurer, G.: Interfacialtensions in binary and ternary liquid liquid-systems, Chem. Eng. Sci., 45, 275-286, 1990.

Ben-Hamo, M., Apelblat, A., and Manzurola, E.: Volumetric properties of aqueous solutions of glutaric acid, J. Chem. Thermodyn., 39, 1071-1076, doi:10.1016/j.jct.2006.12.015, 2007.

Bertram, A. K., Martin, S. T., Hanna, S. J., Smith, M. L., Bodsworth, A., Chen, Q., Kuwata, M., Liu, A., You, Y., and Zorn, S. R.: Predicting the relative humidities of liquid-liquid phase separation, efflorescence, and deliquescence of mixed par- ticles of ammonium sulfate, organic material, and water using the organic-to-sulfate mass ratio of the particle and the oxygen-tocarbon elemental ratio of the organic component, Atmos. Chem. Phys., 11, 10995-11006, doi:10.5194/acp-11-10995-2011, 2011.

Booth, A. M., Topping, D. O., McFiggans, G., and Percival, C. J.: Surface tension of mixed inorganic and dicarboxylic acid aqueous solutions at $298.15 \mathrm{~K}$ and their importance for cloud activation predictions, Phys. Chem. Chem. Phys., 11, 8021-8028, doi:10.1039/B906849j, 2009.

Braban, C. F. and Abbatt, J. P. D.: A study of the phase transition behavior of internally mixed ammonium sulfate - malonic acid aerosols, Atmos. Chem. Phys., 4, 1451-1459, doi:10.5194/acp4-1451-2004, 2004

Cai, B. Y., Yang, J. T., and Guo, T. M.: Interfacial tension of hydrocarbon plus water/brine systems under high pressure, J. Chem. Eng. Data, 41, 493-496, 1996.

Chang, E. I. and Pankow, J. F.: Prediction of activity coefficients in liquid aerosol particles containing organic compounds, dissolved inorganic salts, and water - Part 2: Consideration of phase separation effects by an X-UNIFAC model, Atmos. Environ., 40, 6422-6436, doi:10.1016/j.atmosenv.2006.04.031, 2006.

Chhabra, P. S., Ng, N. L., Canagaratna, M. R., Corrigan, A. L., Russell, L. M., Worsnop, D. R., Flagan, R. C., and Seinfeld, J. H.: Elemental composition and oxidation of chamber organic aerosol, Atmos. Chem. Phys., 11, 8827-8845, doi:10.5194/acp-11-88272011, 2011.

Chmielewska, A. and Bald, A.: Viscosimetric studies of aqueous solutions of dicarboxylic acids, J. Mol. Liq., 137, 116-121, doi:10.1016/j.molliq.2007.05.002, 2008.

Ciobanu, V. G., Marcolli, C., Krieger, U. K., Weers, U., and Peter, T.: Liquid-liquid phase separation in mixed organic/inorganic aerosol particles, J. Phys. Chem. A., 113, 10966-10978, doi:10.1021/Jp905054d, 2009.

Ciobanu, V. G., Marcolli, C., Krieger, U. K., Zuend, A., and Peter, T.: Efflorescence of ammonium sulfate and coated ammonium sulfate particles: Evidence for surface nucleation, J. Phys. Chem. A., 114, 9486-9495, doi:10.1021/Jp103541w, 2010.

Cosman, L. M. and Bertram, A. K.: Reactive uptake of $\mathrm{N}_{2} \mathrm{O}_{5}$ on aqueous $\mathrm{H}_{2} \mathrm{SO}_{4}$ solutions coated with 1-component and 2component monolayers, J. Phys. Chem. A., 112, 4625-4635, doi:10.1021/Jp8005469, 2008.

Cosman, L. M., Knopf, D. A., and Bertram, A. K.: $\mathrm{N}_{2} \mathrm{O}_{5}$ reactive uptake on aqueous sulfuric acid solutions coated with branched and straight-chain insoluble organic surfactants, J. Phys. Chem. A., 112, 2386-2396, doi:10.1021/Jp710685r, 2008.

Cziczo, D. J., Nowak, J. B., Hu, J. H., and Abbatt, J. P. D.: Infrared spectroscopy of model tropospheric aerosols as a function of relative humidity: Observation of deliquescence and crystallization, J. Geophys. Res., 102, 18843-18850, 1997.

Decesari, S., Fuzzi, S., Facchini, M. C., Mircea, M., Emblico, L., Cavalli, F., Maenhaut, W., Chi, X., Schkolnik, G., Falkovich, A., Rudich, Y., Claeys, M., Pashynska, V., Vas, G., Kourtchev, I., Vermeylen, R., Hoffer, A., Andreae, M. O., Tagliavini, E., Moretti, F., and Artaxo, P.: Characterization of the organic composition of aerosols from Rondônia, Brazil, during the LBASMOCC 2002 experiment and its representation through model compounds, Atmos. Chem. Phys., 6, 375-402, doi:10.5194/acp6-375-2006, 2006.

Donahue, N. M., Epstein, S. A., Pandis, S. N., and Robinson, A. 
L.: A two-dimensional volatility basis set: 1. organic-aerosol mixing thermodynamics, Atmos. Chem. Phys., 11, 3303-3318, doi:10.5194/acp-11-3303-2011, 2011.

Erdakos, G. B. and Pankow, J. F.: Gas/particle partitioning of neutral and ionizing compounds to single- and multi-phase aerosol particles. 2. Phase separation in liquid particulate matter containing both polar and low-polarity organic compounds, Atmos. Environ., 38, 1005-1013, doi:10.1016/j.atmosenv.2003.10.038, 2004.

Folkers, M., Mentel, T. F., and Wahner, A.: Influence of an organic coating on the reactivity of aqueous aerosols probed by the heterogeneous hydrolysis of $\mathrm{N}_{2} \mathrm{O}_{5}$, Geophys. Res. Lett., 30, 1644, doi:10.1029/2003g1017168, 2003.

Frank, B. P. and Belfort, G.: Atomic force microscopy for lowadhesion surfaces: Thermodynamic criteria, critical surface, tension, and intermolecular forces, Langmuir, 17, 1905-1912, doi:10.1021/La0011533, 2001.

Fuzzi, S., Andreae, M. O., Huebert, B. J., Kulmala, M., Bond, T. C., Boy, M., Doherty, S. J., Guenther, A., Kanakidou, M., Kawamura, K., Kerminen, V.-M., Lohmann, U., Russell, L. M., and Pöschl, U.: Critical assessment of the current state of scientific knowledge, terminology, and research needs concerning the role of organic aerosols in the atmosphere, climate, and global change, Atmos. Chem. Phys., 6, 2017-2038, doi:10.5194/acp-62017-2006, 2006.

Gilardoni, S., Liu, S., Takahama, S., Russell, L. M., Allan, J. D., Steinbrecher, R., Jimenez, J. L., De Carlo, P. F., Dunlea, E. J., and Baumgardner, D.: Characterization of organic ambient aerosol during MIRAGE 2006 on three platforms, Atmos. Chem. Phys., 9, 5417-5432, doi:10.5194/acp-9-5417-2009, 2009.

Giraldo-Zuniga, A. D., Coimbra, J. S. D., Arquete, D. A., Minim, L. A., da Silva, L. H. M., and Maffia, M. C.: Interfacial tension and viscosity for poly(ethylene glycol) plus maltodextrin aqueous two-phase systems, J. Chem. Eng. Data, 51, 1144-1147, doi:10.1021/Je0600348, 2006.

Goldstein, A. H. and Galbally, I. E.: Known and unexplored organic constituents in the earth's atmosphere, Environ. Sci. Technol., 41, 1514-1521, 2007.

Hallquist, M., Wenger, J. C., Baltensperger, U., Rudich, Y., Simpson, D., Claeys, M., Dommen, J., Donahue, N. M., George, C., Goldstein, A. H., Hamilton, J. F., Herrmann, H., Hoffmann, T., Iinuma, Y., Jang, M., Jenkin, M. E., Jimenez, J. L., Kiendler-Scharr, A., Maenhaut, W., McFiggans, G., Mentel, Th. F., Monod, A., Prévôt, A. S. H., Seinfeld, J. H., Surratt, J. D., Szmigielski, R., and Wildt, J.: The formation, properties and impact of secondary organic aerosol: current and emerging issues, Atmos. Chem. Phys., 9, 5155-5236, doi:10.5194/acp-95155-2009, 2009.

Hanel, G.: The properties of atmospheric aerosol particles as functions of the relative humidity at thermodynamic equilibrium with the surrounding moist air, Adv. Geophys., 19, 73-188, 1976.

Hawkins, L. N., Russell, L. M., Covert, D. S., Quinn, P. K., and Bates, T. S.: Carboxylic acids, sulfates, and organosulfates in processed continental organic aerosol over the southeast Pacific Ocean during VOCALS-REx 2008, J. Geophys. Res., 115, D13201, doi:10.1029/2009jd013276, 2010.

Heald, C. L., Kroll, J. H., Jimenez, J. L., Docherty, K. S., DeCarlo, P. F., Aiken, A. C., Chen, Q., Martin, S. T., Farmer, D. K., and Artaxo, P.: A simplified description of the evolution of organic aerosol composition in the atmosphere, Geophys. Res. Lett., 37, L08803, doi:10.1029/2010g1042737, 2010.

IPCC 2007: Solomon, S., Qin, D., Manning, M., Chen, Z., Marquis, M., Averyt, K. B., Tignor, M., and Miller, H. L.: Climate Change 2007: The physical science basis. Contribution of working group I to the Fourth Assessment Report of the Intergovernmental Panel on Climate Change, Cambridge University Press, Cambridge, United Kingdom and New York, NY, USA, 2007.

Jimenez, J. L., Canagaratna, M. R., Donahue, N. M., Prevot, A. S. H., Zhang, Q., Kroll, J. H., DeCarlo, P. F., Allan, J. D., Coe, H., Ng, N. L., Aiken, A. C., Docherty, K. S., Ulbrich, I. M., Grieshop, A. P., Robinson, A. L., Duplissy, J., Smith, J. D., Wilson, K. R., Lanz, V. A., Hueglin, C., Sun, Y. L., Tian, J., Laaksonen, A., Raatikainen, T., Rautiainen, J., Vaattovaara, P., Ehn, M., Kulmala, M., Tomlinson, J. M., Collins, D. R., Cubison, M. J., Dunlea, E. J., Huffman, J. A., Onasch, T. B., Alfarra, M. R., Williams, P. I., Bower, K., Kondo, Y., Schneider, J., Drewnick, F., Borrmann, S., Weimer, S., Demerjian, K., Salcedo, D., Cottrell, L., Griffin, R., Takami, A., Miyoshi, T., Hatakeyama, S., Shimono, A., Sun, J. Y., Zhang, Y. M., Dzepina, K., Kimmel, J. R., Sueper, D., Jayne, J. T., Herndon, S. C., Trimborn, A. M., Williams, L. R., Wood, E. C., Middlebrook, A. M., Kolb, C. E., Baltensperger, U., and Worsnop, D. R.: Evolution of organic aerosols in the atmosphere, Science, 326, 1525-1529, doi:10.1126/science.1180353, 2009.

Knopf, D. A.: Thermodynamic properties and nucleation processes of upper tropospheric and lower stratospheric aerosol particles, Diss. ETH No. 15103, Zurich, Switzerland, 2003.

Knopf, D. A. and Lopez, M. D.: Homogeneous ice freezing temperatures and ice nucleation rates of aqueous ammonium sulfate and aqueous levoglucosan particles for relevant atmospheric conditions, Phys. Chem. Chem. Phys., 11, 8056-8068, doi:10.1039/B903750k, 2009.

Kostorz, G.: Phase Transformations in Materials, Wiley-VCH, Weinheim, Germany, 409-480, 2001.

Kroll, J. H., Donahue, N. M., Jimenez, J. L., Kessler, S. H., Canagaratna, M. R., Wilson, K. R., Altieri, K. E., Mazzoleni, L. R., Wozniak, A. S., Bluhm, H., Mysak, E. R., Smith, J. D., Kolb, C. E., and Worsnop, D. R.: Carbon oxidation state as a metric for describing the chemistry of atmospheric organic aerosol, Nat. Chem., 3, 133-139, doi:10.1038/Nchem.948, 2011.

Kwamena, N. O. A., Buajarern, J., and Reid, J. P.: Equilibrium morphology of mixed organic/inorganic/aqueous aerosol droplets: Investigating the effect of relative humidity and surfactants, J. Phys. Chem. A., 114, 5787-5795, doi:10.1021/Jp1003648, 2010.

Laguerie, C., Aubry, M., and Couderc, J. P.: Some physicochemical data on monohydrate citric-acid solutions in water - solubility, density, viscosity, diffusivity, $\mathrm{pH}$ of standard solution, and refractive-index, J. Chem. Eng. Data, 21, 85-87, 1976.

Lee, S. H., Murphy, D. M., Thomson, D. S., and Middlebrook, A. M.: Chemical components of single particles measured with Particle Analysis by Laser Mass Spectrometry (PALMS) during the Atlanta SuperSite Project: Focus on organic/sulfate, lead, soot, and mineral particles, J. Geophys. Res., 107, 4003, doi:10.1029/2000jd000011, 2002.

Lewis, E. R.: The effect of surface tension (Kelvin effect) on the equilibrium radius of a hygroscopic aqueous aerosol particle, J. Aerosol Sci., 37, 1605-1617, doi:10.1016/j.jaerosci.2006.04.001, 2006. 
Ling, T. Y. and Chan, C. K.: Partial crystallization and deliquescence of particles containing ammonium sulfate and dicarboxylic acids, J. Geophys. Res., 113, D14205, doi:10.1029/2008jd009779, 2008.

Marcolli, C. and Krieger, U. K.: Phase changes during hygroscopic cycles of mixed organic/inorganic model systems of tropospheric aerosols, J. Phys. Chem. A., 110, 1881-1893, doi:10.1021/Jp0556759, 2006.

Marcolli, C., Luo, B. P., and Peter, T.: Mixing of the organic aerosol fractions: Liquids as the thermodynamically stable phases, J. Phys. Chem. A., 108, 2216-2224, doi:10.1021/Jp0360801, 2004.

Martin, S. T.: Phase transitions of aqueous atmospheric particles, Chem. Rev., 100, 3403-3453, doi:10.1021/Cr990034t, 2000.

Martin, S. T., Rosenoern, T., Chen, Q., and Collins, D. R.: Phase changes of ambient particles in the Southern Great Plains of Oklahoma, Geophys. Res. Lett., 35, L22801, doi:10.1029/2008GL035650, 2008.

McNeill, V. F., Patterson, J., Wolfe, G. M., and Thornton, J. A.: The effect of varying levels of surfactant on the reactive uptake of $\mathrm{N}_{2} \mathrm{O}_{5}$ to aqueous aerosol, Atmos. Chem. Phys., 6, 1635-1644, doi:10.5194/acp-6-1635-2006, 2006.

Murphy, D. M., Cziczo, D. J., Froyd, K. D., Hudson, P. K., Matthew, B. M., Middlebrook, A. M., Peltier, R. E., Sullivan, A., Thomson, D. S., and Weber, R. J.: Single-particle mass spectrometry of tropospheric aerosol particles, J. Geophys. Res., 111, D23s32, doi:10.1029/2006jd007340, 2006.

Murray, B. J.: Inhibition of ice crystallisation in highly viscous aqueous organic acid droplets, Atmos. Chem. Phys., 8, 54235433, doi:10.5194/acp-8-5423-2008, 2008.

Nan, Y. Q., Liu, H. L., and Hu, Y.: Composition, microstructure and rheology of aqueous two-phase cationic/anionic surfactant systems, Colloid Surface A, 277, 230-238, doi:10.1016/j.colsurfa.2005.11.095, 2006.

Ng, N. L., Canagaratna, M. R., Jimenez, J. L., Chhabra, P. S., Seinfeld, J. H., and Worsnop, D. R.: Changes in organic aerosol composition with aging inferred from aerosol mass spectra, Atmos. Chem. Phys., 11, 6465-6474, doi:10.5194/acp-11-64652011, 2011.

Pankow, J. F.: Gas/particle partitioning of neutral and ionizing compounds to single and multi-phase aerosol particles. 1. Unified modeling framework, Atmos. Environ., 37, 3323-3333, doi:10.1016/S1352-2310(03)00346-7, 2003.

Papon, P., Leblond, J., and Meijer, P. H. E.: The Physics of Phase Transitions: Concepts and Applications, Springer, New York, US, 1999.

Parsons, M. T., Mak, J., Lipetz, S. R., and Bertram, A. K.: Deliquescence of malonic, succinic, glutaric, and adipic acid particles, J. Geophys. Res. Atmos., 109, D06212, doi:10.1029/2003jd004075, 2004.

Parsons, M. T., Riffell, J. L., and Bertram, A. K.: Crystallization of aqueous inorganic-malonic acid particles: Nucleation rates, dependence on size, and dependence on the ammonium-to-sulfate, J. Phys. Chem. A., 110, 8108-8115, doi:10.1021/Jp057074n, 2006.

Reid, J. P., Dennis-Smither, B. J., Kwamena, N.-O. A., Miles, R. E. H., Hanford, K. L., and Homer, C. J.: The morphology of aerosol particles consisting of hydrophobic and hydrophilic phases: hydrocarbons, alcohols and fatty acids as the hydrophobic component, Phys. Chem. Chem. Phys., 13, 15559-15572,
doi:10.1039/C1CP21510H, 2011.

Riemer, N., Vogel, H., Vogel, B., Anttila, T., Kiendler-Scharr, A., and Mentel, T. F.: Relative importance of organic coatings for the heterogeneous hydrolysis of $\mathrm{N}_{2} \mathrm{O}_{5}$ during summer in Europe, J. Geophys. Res. Atmos., 114, D17307, doi:10.1029/2008jd011369, 2009.

Shelby, J.: Introduction to glass science and technology, The Royal Society of Chemistry, Cambridge, UK, 1995.

Shulman, M. L., Jacobson, M. C., Carlson, R. J., Synovec, R. E., and Young, T. E.: Dissolution behavior and surface tension effects of organic compounds in nucleating cloud droplets, Geophys. Res. Lett., 23, 277-280, 1996.

Sjogren, S., Gysel, M., Weingartner, E., Baltensperger, U., Cubison, M. J., Coe, H., Zardini, A. A., Marcolli, C., Krieger, U. K., and Peter, T.: Hygroscopic growth and water uptake kinetics of two-phase aerosol particles consisting of ammonium sulfate, adipic and humic acid mixtures, J. Aerosol Sci., 38, 157-171, doi:10.1016/j.jaerosci.2006.11.005, 2007.

Smith, M. L., Kuwata, M., and Martin, S. T.: Secondary organic material produced by the dark ozonolysis of alphapinene minimally affects the deliquescence and efflorescence of ammonium sulfate, Aerosol Sci. Tech., 45, 244-261, doi:10.1080/02786826.2010.532178, 2011.

Spyropoulos, F., Ding, P., Frith, W. J., Norton, I. T., Wolf, B., and Pacek, A. W.: Interfacial tension in aqueous biopolymersurfactant mixtures, J. Colloid Interf. Sci., 317, 604-610, doi:10.1016/j.jcis.2007.10.006, 2008.

Swietlicki, E., Hansson, H. C., Hameri, K., Svenningsson, B., Massling, A., McFiggans, G., McMurry, P. H., Petaja, T., Tunved, P., Gysel, M., Topping, D., Weingartner, E., Baltensperger, U., Rissler, J., Wiedensohler, A., and Kulmala, M.: Hygroscopic properties of submicrometer atmospheric aerosol particles measured with H-TDMA instruments in various environments - a review, Tellus B, 60, 432-469, doi:10.1111/j.16000889.2008.00350.x, 2008.

Tang, I. N. and Munkelwitz, H. R.: An investigation of solute nucleation in levitated solution droplets, J. Colloid Interf. Sci., 98, 430-438, 1984.

Tang, I. N. and Munkelwitz, H. R.: Water activities, densities, and refractive-indexes of aqueous sulfates and sodiumnitrate droplets of atmospheric importance, J. Geophys. Res., 99, 18801-18808, 1994.

Thornton, J. A. and Abbatt, J. P. D.: $\mathrm{N}_{2} \mathrm{O}_{5}$ reaction on submicron sea salt aerosol: Kinetics, products, and the effect of surface active organics, J. Phys. Chem. A., 109, 10004-10012, doi:10.1021/Jp054183t, 2005.

Topping, D. O., McFiggans, G. B., Kiss, G., Varga, Z., Facchini, M. C., Decesari, S., and Mircea, M.: Surface tensions of multicomponent mixed inorganic/organic aqueous systems of atmospheric significance: measurements, model predictions and importance for cloud activation predictions, Atmos. Chem. Phys., 7, 2371-2398, doi:10.5194/acp-7-2371-2007, 2007.

Torza, S. and Mason, S. G.: 3-Phase Interactions in shear and electrical fields, J. Colloid Interf. Sci., 33, 67-83, 1970.

Varga, Z., Kiss, G., and Hansson, H.-C.: Modelling the cloud condensation nucleus activity of organic acids on the basis of surface tension and osmolality measurements, Atmos. Chem. Phys., 7, 4601-4611, doi:10.5194/acp-7-4601-2007, 2007.

Virtanen, A., Joutsensaari, J., Koop, T., Kannosto, J., Yli-Pirilä, P., 
Leskinen, J., Mäkelä, J. M., Holopainen, J. K., Pöschl, U., Kulmala, M., Worsnop, D. R., and Laaksonen, A.: An amorphous solid state of biogenic secondary organic aerosol particles, Nature, 467, 824-827, doi:10.1038/nature09455, 2010.

Weingartner, E., Gysel, M., and Baltensperger, U.: Hygroscopicity of aerosol particles at low temperatures. 1. New low-temperature H-TDMA instrument: Setup and first applications, Environ. Sci. Technol., 36, 55-62, doi:10.1021/Es010054o, 2002.

Yeung, M. C., Lee, A. K. Y., and Chan, C. K.: Phase transition and hygroscopic properties of internally mixed ammonium sulfate and adipic acid (AS-AA) particles by optical microscopic imaging and Raman spectroscopy, Aerosol Sci. Tech., 43, 387399, doi:10.1080/02786820802672904, 2009.

Yu, H., Kaufman, Y. J., Chin, M., Feingold, G., Remer, L. A., Anderson, T. L., Balkanski, Y., Bellouin, N., Boucher, O., Christopher, S., DeCola, P., Kahn, R., Koch, D., Loeb, N., Reddy, M. S., Schulz, M., Takemura, T., and Zhou, M.: A review of measurement-based assessments of the aerosol direct radiative effect and forcing, Atmos. Chem. Phys., 6, 613-666, doi:10.5194/acp-6-613-2006, 2006.

Zardini, A. A., Sjogren, S., Marcolli, C., Krieger, U. K., Gysel, M., Weingartner, E., Baltensperger, U., and Peter, T.: A combined particle trap/HTDMA hygroscopicity study of mixed inorganic/organic aerosol particles, Atmos. Chem. Phys., 8, 55895601, doi:10.5194/acp-8-5589-2008, 2008.

Zhang, Q., Jimenez, J. L., Canagaratna, M. R., Allan, J. D., Coe, H., Ulbrich, I., Alfarra, M. R., Takami, A., Middlebrook, A. M., Sun, Y. L., Dzepina, K., Dunlea, E., Docherty, K., DeCarlo, P. F., Salcedo, D., Onasch, T., Jayne, J. T., Miyoshi, T., Shimono, A., Hatakeyama, S., Takegawa, N., Kondo, Y., Schneider, J., Drewnick, F., Borrmann, S., Weimer, S., Demerjian, K., Williams, P., Bower, K., Bahreini, R., Cottrell, L., Griffin, R. J., Rautiainen, J., Sun, J. Y., Zhang, Y. M., and Worsnop, D. R.: Ubiquity and dominance of oxygenated species in organic aerosols in anthropogenically-influenced Northern Hemisphere midlatitudes, Geophys. Res. Lett., 34, L13801, doi:10.1029/2007g1029979, 2007.
Zhang, Y. H. and Chan, C. K.: Understanding the hygroscopic properties of supersaturated droplets of metal and ammonium sulfate solutions using Raman spectroscopy, J. Phys. Chem. A., 106, 285-292, doi:10.1021/Jp012694j, 2002.

Zobrist, B., Marcolli, C., Pedernera, D. A., and Koop, T.: Do atmospheric aerosols form glasses?, Atmos. Chem. Phys., 8, 52215244, doi:10.5194/acp-8-5221-2008, 2008.

Zuend, A., Marcolli, C., Luo, B. P., and Peter, T.: A thermodynamic model of mixed organic-inorganic aerosols to predict activity coefficients, Atmos. Chem. Phys., 8, 4559-4593, doi:10.5194/acp8-4559-2008, 2008.

Zuend, A., Marcolli, C., Peter, T., and Seinfeld, J. H.: Computation of liquid-liquid equilibria and phase stabilities: implications for RH-dependent gas/particle partitioning of organic-inorganic aerosols, Atmos. Chem. Phys., 10, 7795-7820, doi:10.5194/acp10-7795-2010, 2010.

Zuend, A., Marcolli, C., Booth, A. M., Lienhard, D. M., Soonsin, V., Krieger, U. K., Topping, D. O., McFiggans, G., Peter, T., and Seinfeld, J. H.: New and extended parameterization of the thermodynamic model AIOMFAC: calculation of activity coefficients for organic-inorganic mixtures containing carboxyl, hydroxyl, carbonyl, ether, ester, alkenyl, alkyl, and aromatic functional groups, Atmos. Chem. Phys., 11, 9155-9206, doi:10.5194/acp-11-9155-2011, 2011. 